\title{
Psychiatry and the Presumption of Expertise: Flipping Coins in the Courtroom
}

\author{
by \\ Bruce J. Ennis* and Thomas R. Litwack**
}

TABLe of Contents

INTRODUCTION

I. Professional Literature on the Reliability and VALIDITY OF PSYCHIATRIC JUDGMENTS

A. The Reliability of Psychiatric Judgments _._____ 699

B. The Validity of Psychiatric Judgments _________ 708

1. The validity of diagnosis ______ 708

2. The validity of predictions of dangerousness ___ 711

3. The validity of predictions of the need for hospitalization and treatment

4. The validity of predictions of the effect of hospitalization and treatment

II. Some Reasons Why Psychiatric Judgments Are UnRELIABLE AND INVALID

A. Orientation, Training, and Experience _._____ 720

B. Context ___ 722

C. Time _ 723

D. Class, Culture, Race, and Sex ___ 724

E. Personal Bias __________ 726

F. Inadequacies of the Diagnostic System and the Ambiguity of Psychiatric Data

G. Additional Reasons Why Psychiatric Predictions of Dangerousness Are Invalid

* A.B., Dartmouth College (1962); J.D., University of Chicago Law School (1965). Staff Attorney, New York Civil Liberties Union, and Mental Health Law Project.

** A.B., Dartmouth College (1964); Ph. D., New York University (1972); J.D., New York University (1974). Assistant Professor of Psychology, John Jay College of Criminal Justice, the City University of New York.

We wish to acknowledge substantial research assistance from Nancy Lee Ennis, J.D., Bonnie Gitlin, M.A., and Carl F. Wiedemann, Ph. D., and critical suggestions from Israel Zwerling, M.D., Ph.D. 
III. Legal Consequences and Recommendations

A. Psychiatrists Should Not Be Permitted To Testify As "Experts" in Civil Commitment Proceedings

1. Psychiatric judgments are not sufficiently reliable or valid to justify their admissibility under traditional rules of evidence

2. Psychiatric judgments do not convey meaningful or otherwise unavailable information about the issues relevant in a civil commitment proceeding

3. The admission of psychiatric judgments in a civil commitment proceeding denies prospective patients due process

B. If Psychiatrists Are Permitted To Testify As Experts, The Prospective Patient Should Be Afforded a Meaningful Opportunity To Cross-Examine And To Call Expert Witnesses On His Behalf

1. Cross-examination _.____________ 743

2. Expert witnesses for the prospective patient _.__ 746

C. Non-Judicial Commitment Should Be Abolished Or Severely Circumscribed

D. "Mental Illness" And/Or "Need For Care And Treatment" Should Not Be Sufficient Grounds For Commitment

E. The Criteria for Commitment on the Basis of "Dangerousness" Should Be Severely Circumscribed

F. Commitment Should Require Proof of Mental Illness and Dangerousness Beyond A Reasonable Doubt

A critical aspect of the civil commitment process is the extraordinary influence psychiatrists exert in the determination of who shall be involuntarily hospitalized. At commitment hearings, psychiatrists are permitted and even encouraged to offer their opinions on the ultimate issues-is the prospective patient "Inentally ill," or "dangerous," or "in need of care and treatment?" Psychiatrists are also allowed to describe the potential patient using technical terminology and psychiatric diagnoses. Judges and juries, believing that psychiatrists are experts, usually defer to their judginents and recommendations. ${ }^{1}$

1. See, e.g., Cohen, The Function of the Attorney in the Commitment of the Mentally Ill, 44 TEXAS L. Rev. 424 (1966) [hereinafter cited as Cohen], and The Administration of Psychiatric Justice: Theory and Practice in Arizona, 13 ARIz. L. REv. 1 (1971) (reporting the deference of judges to psychiatric opinion in civil commitment proceedings) [hereinafter cited as Project]; Rosenberg \& McGarry, Competency for Trial: The Making of an Expert, 128 AM. J. PsYchint. 1092, 1092-95 
In many states persons who are not considered physically dangerous to themselves or others can be hospitalized involuntarily, even without judicial proceedings, if two psychiatrists certify that the prospective patient is "mentally ill" and in need of treatment. ${ }^{2}$ No state authorizes two laymen - a grocer and a clerk for example-to hospitalize a neighbor simply because the laymen believe he or she is mentally ill and in need of treatment. This extraordinary power is given to psychiatrists but not to laymen because legislators and judges assume that psychiatrists are umiquely qualified to determine when an individual requires hospitalization.

This assumption of expertise rests upon two further assumptions: that psychiatrists are able to reach conclusions that are reliable, that is, that other psychiatrists would agree with those conclusions; and that those conclusions are valid, that is, that they accurately reflect reality. Unfortunately, judges and legislators are not aware of the enormous and relatively consistent body of professional literature questioning the reliability and validity of psychiatric evaluations and predictions. So far as we are aware, the relevant professional literature has never been collected and analyzed in a legal periodical. ${ }^{3}$

In this article we examine ${ }^{4}$ the assumptions that psychiatrists are "expert" at rcsolving the issues relevant to a civil commitment proceeding and that psychiatric opinions and terminology assist the judge or jury in reaching accurate and humane decisions. ${ }^{5}$ Based upon our

(1972) (competency to stand trial determinations); Weihofen, Detruding the Experts, 1973 WASHINGTON U. L. QUARTERLY 38 (regarding sanity-insanity determinations) [hereinafter cited as Detruding].

2. See, e.g., N.Y. MeNTal Hygiene LAW, \$ 31.27 (McKinney 1973).

3. By "professional literature" we mean articles written by psychiatrists, psychologists, physicians, statisticians, behavioral scientists, and others appearing in journals commonly read by inental health professionals. This category would imclude, for example, the Journal of the American Psychiatric Association, the Journal of the American Orthopsychiatric Association, the Journal of Abnormal and Social Psychology, the Annual Review of Psychology, and so forth. We wish also to acknowledge the assistance of the National Institute of Mental Health Clearinghouse, which supplied us abstracts of all relevant studies and articles-published and unpublished-contained in their computerized files.

4. We use the word "examme," rather than "re-examine," because psychiatrists have never been required to prove their expertise. In one of the earliest cases permitting "medical men" to testify as experts on issues of "sanity or insanity," Justice Harlan thought it sufficient that physicians "are supposed to have become, by study and experience, familiar with the symptoms of mental disease, and, therefore qualified to assist the court or jury in reaching a correct conclusion." Connecticut Mutual Life Ins. Co. v. Lathrop, 111 U.S. 612, 618 (1884) (emphasis added).

5. Much of the relevant literature has been collected and analyzed in an excellent although hard to obtain book by J. Ziskin, Coping with Psychiatric and Psychological Testimony [heremafter cited as ZisknN] (available froin Law and Psychology Press, 202 South Rexford Drive, Beverly Hills, California 90212), which we found extremely useful. Ziskin also concludes that 
reading of the professional literature, we have concluded that (a) there is no evidence warranting the assumption that psychiatrists can accurately determine who is "dangerous"; (b) there is little or no evidence that psychiatrists are more "expert" in making the predictions relevant to civil commitinent than laymen; (c) "expert" judgments made by psychiatrists are not sufficiently reliable and valid to justify nonjudicial hospitalization based on such judgments; (d) the constitutional rights of individuals are seriously prejudiced by the admissibility of psychiatric terminology, diagnoses, and prediotions, especially those of "dangerous" behavior; and therefore (e) courts should limit testimony by psychiatrists to descriptive statements and should exclude psychiatric diagnoses, judgments, and predictions.

In short, we believe there is no evidence that psychiatric opinions and terminology clarify rather than confuse the issues in a civil commitment proceeding, and there is good reason to believe that judges and juries could function quite adequately in a civil commitment proceeding without "expert" opinion testimony.

We intend in this Article to provide legislatures and courts with an extensive overview of the professional literature in order to encourage them to reevaluate the presumption of psychiatric expertise and to determine the propriety of "expert" testimony in commitment proceedings. Specifically, Pant I will summarize the literature on the reliability and validity of psychiatric judgments; ${ }^{6}$ Part II identifies a number of factors that combine to limit the reliability and validity of psychiatric judgments; and Pant III considers the legal consequences of our findings and recommends changes in the law to reduce or eliminate the risk of error inherent in reliance on such judgments. Although our conclusions will be critical of the current role of psychiatrists in civil commitment proceedings, it should be emphasized that we do not disparage the abilities or effonts of particular psychiatrists to assist patients who seek their help. Our conclusions are not an attack on psychiatry per se, but only a criticism of the current reliance on psychiatric expertise in civil commitment proceedings.

... despite the ever increasing utilization of psychiatric and psychological evidence in the legal process, such evidence frequently does not meet reasonable criteria of admissibility and should not be admitted in a court of law and Id. at 1 .

if admitted should be given little or no weight.

6. Judgments by psychologists, including those based on clinical examination and those based upon psychological tests, are also of limited reliability and validity. See ZiskTn, supra note 5.

But since this Article is about the civil commitment process, in which psychologists rarely participate, we are concerned primarily with an examination of the reliability and validity of judgments made by psychiatrists. 


\section{The Professional Literature on the Reliability and VALIDITY OF PsychIATRIC JUdGMENTS}

Before analyzing the professional literature it is necessary to define a few terms and make a few observations. "Reliability" and "validity" are not synonyms; rather, they are used in the professional literature as words of art and refer to quite different concepts.

"Reliability" does not have a precise meaning, ${ }^{7}$ but as used herein it refers to the probability or frequency of agreement when two or more independent observers answer the same question (for example, what is Mr. Smith's diagnosis? Is Smith dangerous?) If representative pairs of psychiatrists, imterviewing a representative sample of prospective patients, usually agree that each individual is or is not "dangerous," the judgment of "dangerousness" is said to be reliable. Conversely, if pairs of psychiatrists would not usually agree whether such individuals are dangerous, that judgment is said to be unreliable. ${ }^{8}$

"Validity," on the other hand, refers not to how likely psychiatrists are to agree about a particular judgment but to how accurate their judgments are. If every psychiatrist in the world agrees that Smith would commit a dangerous act if released from the hospital, that judg. ment would be 100 percent reliable. But if Smith were released and does not commit a dangerous act, the judgment would be invalid. Similarly, psychiatric judgments of "dangerousness" would be generally reliable if most observers would agree whether or not given imdividuals are dangerous, yet generally invalid if those judgments usually would be wrong. ${ }^{9}$

Another way to understand the difference between reliability and validity is to think of reliability as referring to the degree of correlation

7. See L. Cronbach, Essentials of Psychological Testing 173-182 (3d ed. 1970) [hereinafter cited as CRoNBACH].

8. In general, the "reliability" of a judgment will depend on the sample of interviewees. In the judgment of dangerousness, for example, when the sample is of the general population, there should be considerable agreement among psychiatristsand among laymen-because only a small percentage of the sample would present a substantial question of dangerousness. The same should be true when the sample consists only of individuals who recently have committed violent acts and continue to express violent intentions. In the typical civil commitment proceeding, however, there is usually some evidence, but not overwhelming evidence, of dangerousness or harmlessness. An example would be an individual exhibiting delusions of persecution but having no history of violent behavior. Many individuals subject to civil commitment proceedings present such a questionable picture, especially when dangerousness-to-self is included in the concept of dangerousness. It is the reliability of predictions of "dangerousness" in these ambiguous-but-typical contexts that is in issue.

9. We will see an example of such a phenomenon when we discuss the Baxstrom studies, infra in text accompanying notes 58-64. 
or correspondence of judgment between professionals using the same method, and validity as referring to the degree of correlation or correspondence between the judgment reached by the professionals and some fact in the external world.

Even though the validity of psychiatric judgments is of primary importance, we are interested in their reliability as well. For psychiatric judgments are likely to be no more valid, and probably less valid, than they are reliable. ${ }^{10}$ For example, if predictions of dangerousness are 50 percent reliable there is only one chance in two that a second psychiatrist would agree with a first that Smith is "dangerous." If psy. chiatrists cannot generally agree whether Smith is dangerous, we cannot be confident about the accuracy of any individual prediction that Smith is dangerous. Smith is either dangerous or not dangerous, schizophrenic or not schizophrenic. When psychiatrists disagree, when their judgments are unreliable, it is evident that at least some of them are wrong. The niore likely psychiatrists are to disagree, the greater is the likelihood that an individual judgment is invalid. The reliability of a judgment also assumes major significance because reliability is usually easier to ascertain then validity. If validity studies are not available, examination of the reliability of psychiatric judgments provides a basis for estimating the upper limits of validity.

It should also be noted, before we proceed to review the literature, that the ultimate question is not whether psychiatric judgments are at all valid, but whether they are sufficiently valid to meet the traditional criteria for the admissibility of "expert," conclusory testimony and, in a civil commitment context, whether they are sufficiently valid to permit involuntary deprivations of liberty based on such judg. ments without violating the constitutional rights of prospective patients.

Thus, if psychiatric predictions and opinions are no more valid than those of laymen such conclusions should not be admissible, if similar conclusions by laymen would not be admissible-and certainly they should not be accorded any special weight. Special weight should be given only to the opinions of a witness who can demonstrate two things: (a) that he uses techniques and knowledge not available to laymen to arrive at his conclusions; and (b) that the application of these techniques results in judgments that are significantly more valid than the judgments laymen otherwise would reach. ${ }^{11}$

10. Regarding the importance of reliability, see Hine \& Feather, Psychiatry and the Philosophy of Science II: Some Approaches to Conceptual Problems, $133 \mathrm{~J}$. Nerv. MENT. Dis. 25 (1961). For an example where validity is higher than reliability, see Raines \& Rohrer, The Operational Matrix of Psychiatric Practice, I Consistency and Variability in Interview Impressions of Different Psychiatrists, 111 AM. J. PsYCHIAT. 721, 733 (1955) [hereinafter cited as Raines \& Rohrer].

11. See, e.g., Carmody v. Aho 251 Minn. 19, 86 N.W.2d 692, 695 (1957). 
In other words, a judgment about another person's mental condition or propensity to engage in dangerous behavior should not be deferred to as an expert judgment simply because it is made by a person who happens to be a psychiatrist. Before a psychiatrist's conclusory judgment can be considered an adımissible expert judgment-much less worthy of special attention-the psychiatrist must employ techniques and apply knowledge that have been shown to produce substantially more reliable and valid results than could the techniques and knowledge available to laymen. It has been assumed that something in the education, training, experience, and techniques of psychiatrists makes their judgments more reliable and more valid than those judgments would be in the absence of such education, training, experience, and techniques. That assumption may be incorrect.

But even if psychiatric judgments were somewhat more valid than those of laymen, we will argue that they should nevertheless be inadmissible in civil commitment hearings. Within constitutional limitations, only society can determine how valid a judgment must be-how certainly correct-in order to justify relying on it to deprive an individual of liberty. As we will demonstrate, the results of other "scientific" methods such as polygraph examinations provide far more valid judgments than those of psychiatrists but generally have been excluded from the courtroom as insufficiently trustworthy to justify demal of important rights. Psychiatric judgments, though less valid, are generally admissible. This Article questions whether such a policy is rational or constitutional.

\section{A. The Reliability of Psychiatric Judgments}

Theoretically, there are at least four kinds of psychiatric judgments that may be relevant in a civil commitment proceeding: is the prospective patient "mentally ill;" is he dangerous; does his condition require or justify involuntary hospitalization and treatment; will involuntary hospitalization and treatment cure or benefit the prospective patient? How often do psychiatrists agree or disagree in their answers to these four questions? Or, phrased differently, how reliable are their judgments in each of these four areas?

There are several studies of the reliability of psychiatric diagnosis and we will discuss those studies in a moinent. But there are almost no studies of the reliability of psychiatric judgments in the remaining three areas. In other words, we do not know how often two or more psychiatrists would agree that a given person is dangerous, requires hospitalization, and will benefit from involuntary treatment. The consistency of opinions expressed on these issues, often of the utmost importance in a commitment hearing, is, as far as we have been able to 
determine, unstudied and unknown. We believe that any claim to reliability im each of these three areas has yet to be demonstrated by empirical studies. Accordingly, in this Section we will be concerned almost exclusively with the reliability of psychiatric diagnoses.

It is necessary to preface our discussion with a brief discription of basic diagnostic terminology. Studies usually focus upon the reliability of certaim broad diagnostic categories: the organic psychoses, the functional psychoses, the neuroses, the character disorders, and, in some studies, "normality."12

Patients are described as "psychotic" by the official diagnostic manual of the American Psychiatric Association when:

their mental functioning is sufficiently impaired to interfere grossly with their capacity to meet the ordinary demands of life. The impairment may result from a serious distortion in their capacity to recognize reality. Hallucinations and delusions, for example, may distort their perceptions. Alterations of mood may be so profound that the patient's capacity to respond appropriately is grossly impaired. Deficits in perception, language and memory may be so severe that the patient's capacity for mental grasp of his situation is effectively lost. ${ }^{13}$

There are two major subtypes of psychosis: the organic and the functional. An organic psychosis has a known psysiological cause; a functional psychosis does not.

"Neurosis" refers to a condition in which there is no loss of reality testing, but the individual nevertheless suffers from considerable experienced anxiety or from one of many "symptoms," such as compulsive behavior or some type of phobia. The term "symptom" refers to sone form of behavior or emotional state which the individual himself finds to be debilitating and which he experiences as foreign to his basic personality. ${ }^{14}$

The diagnosis of "character disorder," now more commonly referred to as "personality disorder," 15 refers to deeply ingrained, maladaptive, and self-defeating-but nonpsychotic-patterns of behavior.

12. We believe this diagnostic scheme is artificial and disfunctional and thus summarize these definitions without endorsing their meaningfulness or usefulness.

13. American Psychiatric Association, DSM-II: Diagnostic and Statistrcal Manual of Mental Disorders 23 (2d ed. 1968) [hereinafter cited as DSM-Ir]. For a general critical evaluation of DSM-II emphasizing in particular the lack of specificity and consistency in the definition of various terms contained therein, see Jackson, The Revised Diagnostic and Statistical Manual of the American Psychiatric Association, 127 AM. J. PsYchiat. 65 (1970) [hereinafter cited as Jackson].

14. Debilitating or self-defeating behavior is called a "syinptom" because it supposedly both manifests and masks "deeper" problems. This supposition is a matter of considerable professional dispute which need not be considered here.

15. See DSM-II, supra note 13 , at 41 . 
For example, character disorders include impulsive behavior such as alcoholism or drug dependence, anti-social behavior, or personality characteristics that severely interfere with social relationships, such as chronic, undue suspiciousness or excessive shyness. Unlike the neuroses which are characterized by relatively specific and episodic symptoms, the character disorders are much more generalized self-defeating patterns of behavior. It is sometimes said of individuals diagnosed as possessing character disorders that their personality is their symptom. A diagnosis of "normal" can best be defined as the absence of any identifiable psychosis, neurosis, or character disorder.

Within each broad diagnostic category are subcategories, and there are subcategories within the subcategories. For example, the three major subcategories of functional psychosis are schizophrenia, the affeotive psychoses, and the paranoid states; while within the subcategory of schizophrenia there are several subtypes including the simple type, the catatonic type, the paranoid type, the hebephrenic type, and others. The following official definition of schizophrenia illustrates the breadth of this diagnostic category:

[Schizophrenia] includes a group of disorders manifested by characteristic disturbances of thinking, mood and behavior. Disturbances in thinking are marked by alterations of concept formation which may lead to misinterpretations of reality and sometimes to delusions and hallucinations, which frequently appear psychologically selfprotective. Corollary mood changes include anbivalent, constricted and inappropriate emotional responsiveness and loss of empathy with others. Behavior may be withdrawn, regressive and bizarre. The schizophrenics, in which the mental status is attributable primarily to a thought disorder are to be distinguished from the mood affective illnesses . . . which are dominated by a mood disorder. The Paranoid states . . . are distinguished from schizophrenia by the narrowness of their distortions of reahity and by the absence of other psychotic symptoms ....10

The literature indicates that psychiatric diagnoses using these categories are not very reliable. According to Ziskin, "the most coinmon research findings indicate that, on the average, one cannot expect to find agreenent in more than about $60 \%$ of cases between two psychiatrists." 17 The chances of a second psychiatrist agreeing with the diagnosis of a first psychiatrist "are barely better than 5050; or stated differently, there is about as inuch cliance that a different expert would come to some different conclusion as there is that the other would agree."18

16. Id. at 33. This definition also seems unduly vague to us.

17. Ziskin, supra note 5, at 123.

18. Id. at 126 . 
Actually, as we shall see, the reliability of psychiatric judgments of specific diagnostic categories (schizophrenia, paranoid type, depressive reaction, passive-aggressive personahty, and so on) is even lower-somewhere in the neighborhood of 40 percent. In other words, if a first psychiatrist testifies that a prospective patient suffers from involutional melancholia or some other specific, nonorganic diagnosis, it is more likely than not that a second psychiatrist would disagree.

In an: early study Ash measured the diagnostic agreement between two or three psychiatrists who jointly interviewed 52 patients in a psychiatric clinic. ${ }^{19}$ The three psychiatrists agreed on specific diagnoses in only 21 percent of the cases, and totally disagreed in 31 percent. When asked whether a patient fit into one of the more general categories of psychopathology (mental deficiency, character disorder, psychosis, neurosis, and normal) pairs of psychiatrists agreed from 58 to 67 percent of the time, and the trio of psychiatrists agreed only 46 percent of the time. The Ash study suggests that specific psychiatric diagnoses (such as hysterical neurosis, or psychotic depression) are hardly rehable at all, and that broader categories are of linited reliability. ${ }^{20}$ Asli found that only in 3 of 22 cases did all three psychiatrists agree that the patient was "pathologically abnormal."21

Schmidt and Fonda conducted a study that obtained somewhat more positive results. ${ }^{22}$ Each of 427 state hospital patients was diagnosed by pairs of psychiatrists (a psychiatric resident and a chief psychiatrist) under realistic conditions, using the then standard diagnostic system. They found that: a) the diagnosis of organic psychosis was made very reliably (92 percent of the patients diagnosed as "organic" by the chief psychiatrists were also diagnosed as such by the residents); b) the diagnosis of nonorganic psychosis was fairly reliable ( 80 percent agreement); and c) the diagnosis of nonpsychotic disturbances was nioderately reliable (71 percent agreement).

However, agreement as to the major subtype of each of these three categories (11 subtypes in all) was obtained in only about 50

19. Ash, The Reliability of Psychiatric Diagnosis, 44 J. ABN. \& Soc. PsXCH. 272 (1949) [hereinafter cited as Ash].

20. This study utilized patients with relatively minor problems so diagnosis was more difficult than diagnosis of individuals with more serious problems would have been. See Zubin, Classification of the Behavior Disorders, 18 ANN. Rev. PsxcH. 373 (1967) [hereinafter cited as Zubin]. However, the psychiatrists involved jointly interviewed the patients, which should have increased the rate of agreement by reducing the variations in patient behavior and information that would occur from separate interviews. See also Ziskin, supra note 5, ch. 4.

21. Ash, supra note 19 , at 275.

22. Schmidt \& Fonda, The Reliability of Psychiatric Diagnosis: A New Look, 52 J. ABN. \& Soc. PSYCH. 262 (1956). 
percent of the cases and was almost absent in cases of nonsociopathic, nonpsychotic disturbances. For example, the clinicians could agree whether a nonorganic psychosis was "involutional," "affective," or "schizophrenic" in only 47 percent of the cases.

Norris compared the diagnoses given 6,263 patients at an observation unit and then again a few weeks later at a mental institution. The overall rate of agreement was only 60 percent. Yet, when organic cases-about which there was substantial agreenient-were excluded, the rate of agreement on the existence and nature of neuroses and character disorders dropped to 54 percent and 43 percent, respectively. This low level of agreement occurred despite the hospital diagnostician's knowledge of the original diagnosis, which would tend to increase the incidence of diagnostic agreement. ${ }^{23}$

Beck and his co-workers designed their research to correct the flaws of previous studies. ${ }^{24}$ Instead of measuring actual diagnostic reliability, they examined psychiatric judgments under conditions designed to discern the potential reliability of diagnosis. ${ }^{25}$ Nevertheless, even under such reliability-maximizing conditions they found the average percentage of agreement for specific diagnoses was only 54 percent (ranging from 33 to 61 percent between different pairs of psy- , chiatrists) and that regarding one important patient characteristic, the severity of depression, there was only 59 percent agreement. When only the major divisions of psychosis, neurosis, and character disorder were used to classify patients, the rate of agreement was 70 percent.

Studies of reliability conducted under such controlled conditions produce higher rates of diagnostic reliability than are likely to be obtained in actual psychiatric practice. There the lack of controls means that such factors as imexperienced or incompetent psychiatrists, particularized interviewing techniques and conditions, definitional ambignities and biases, semantic differences, and so on all contribute to lower

23. V. NoRris, Mental Illness In London $42-53$ (Maudsley Monographs No. $6,1959)$.

24. Beck, Ward, Mendelson, Mock \& Erbaugh, Reliability of Psychiatric Diagnosis: A Study of Consistency of Clinical Judgments and Riatings, 119 AM. J. PsYCHIAT. 351, 352-55 (1962) [hereinafter cited as Beck, et al.]. This study, the Schmidt and Fonda study, supra note 22, and 15 related studies are described in Falek \& Moser, Classification in Schizophrenia: Historical Review, Current Status and Significance, ACADEMY of SCIENCES, U.S.S.R. (1974) (presented at World Psychiatric Association International Symposium On Aspects of Schizophrenia at Tbilisi, G.S.S.R. October 12, 1973) [hereinafter cited as Falek \& Moser]. See especially Table 3, "Diagnostic Concurrence in Schizophrenia".

25. The psychiatrists were all experienced, and prior to the experiment they discussed various diagnostic categories, ironed out semantic difficulties, and reached a consensus regarding the specific criteria for each of the categories. According to the authors, considerablc discussion about particular "diagnostic descriptions" contained in the official diagnostic manual was necessary to minimize differences. 
diagnostic reliability. ${ }^{26}$ As a result, Beck's study suggests the maximum reliability obtainable at the present time. Beck noted that the rate of agreement regarding particular diagnoses in actual practice is likely to be between 32 and 42 percent. He concluded that " . . the rate of agreement of 54 percent for refined diagnostic categories [which, again, is the optimal rather than actual rate] is not adequate for research. Moreover it is questionable whether the rate of 70 percent agreement recorded for the major divisions (neurosis, psychosis, and character disorder) would be considered adequate for research."27 Consider the significance of that conclusion, "not adequate for research:" a research team cannot rely upon a psychiatrist's judgment that a given person is schizophrenic, but judges and juries do rely on it where personal liberty is at stake.

As we have seen, broad diagnostic categories are more reliable than specific diagnostic categories. But in many instances even a broad diagnosis can be quite unreliable. In one study, for example, 43 experienced psychiatrists diagnosed an individual after viewing a filmed interview. They could not even agree whether the individual was or was not psychotic; 17 psychiatrists thought he was, and the other 26 believed he was not. ${ }^{28}$

Mehlman used a different technique to study diagnostic reliability, and yet produced findings similar to the studies already discussed. ${ }^{20}$ Psychiatrists in a mental hospital were randomly assigned patients for diagnosis. Since the assignments were random, any major differences in the frequency with which the psychiatrists arrived at particular diag-

26. For discussion of these and other factors which affect psychiatric judgments in practice, see Part II, infra.

27. Beck, et. al., supra note 24 , at 355 . Though the reliability of the major diagnostic categories may appear to be fairly high, at least under "good" conditions, two caveats should be noted. First, the broader the diagnostic category, the less clearly it specifies what particular symptoms or behavior the patient manifested (much less their underlying causes). Second, such broad categorization masks great differences in the degree or severity of pathology that can exist within the categories. In short, the broader the category, the less valid or meaningful it becomes.

28. Katz, Cole \& Lowery, Studies of the Diagnostic Process: The Influence of Symptom Perception, Past Experience, and Ethnic Background in Diagnostic Declsions, 125 AM. J. PSYchIAT. 937 (1969) [hereinafter cited as Katz, Cole \& Lowery]. See also, Copeland, Cooper, Kendall \& Gourlay, Differcnces in Usage of Diagnostic Labels amongst Psychiatrists in the British Isles, 118 BRTISH J. PsYCHIAT. 629 (1971) [hereinafter cited as Copeland, et al.].

It is conceivable that some of the differences in diagnoses made by psychiatrists observing such a filined interview might be attributed to their inability to structure the interview in the way they might in their actual practice; but considering the results of other studies comparing individual interviews, and considering the additional sources of error introduced thereby, we think it likely that reliability studies based on film inter views overestimate reliability.

29. Mehlman, The Reliability of Psychiatric Diagnoses, 47 J. ABN. \& Soc PsYCr. 577 (1952). 
noses would tend to indicate the idiosyncratic nature of their judgments. In fact, the differences in the frequency of diagnoses made by the psychiatrists were significantly greater than would be statistically probable by chance, suggesting that the test participants did indeed display personal preferences for specific diagnoses. This, of course, would reduce the chance of their agreeing in any given case.

Another study using a similar mothodology considered the diag. noses assigned to female patients who were randomly assigned to each of three wards. ${ }^{30}$ Independent investigation confirmed that the patients did not differ from ward to ward in socio-economic characteristics. The percentage of patients diagnosed as schizophrenic varied among wards from 23 to 36 percent; those diagnosed as neurotic from 30 to 45 percent; and those diagnosed as having a character disorder from 12 to 22 percent. These differences were all statistically significant. In other words, there was less than one chance in 20 that they were due to chance differences in patient assignment. Moreover, on one ward which had three different chief psychiatrists over a two-year period the percentage of cases diagnosed as schizophremic varied from 22 percent under one psychiatrist to 67 under another; similarly, the percentage diagnosed as character disorder varied from 15 to 56 percent even though there was every reason to believe that, as a group, there were no differences in patient populations during the tenure of each psychiatrist.

In a lengthy review, Zubin surveyed the major studies of diagnostic reliability conducted before 1968 , including, but not limited to, those of Ash, Schmidt and Fonda, Beck, Norris, Mehlman, and Pasamanick. ${ }^{31}$ He concluded that:

[T] he degree of overall agreement between different observers with regard to specific diagnoses is too low for individual diagnosis. The overall agreement on general categories of diagnosis, although somewhat higher [64-84 percent], still leaves much to be desired. The evidence for low agreement across specific diagnostic categories is all the more surprising since, for the most part, the observers in any one study were usually quite similar in orientation, training, and background. ${ }^{32}$

Additional studies suggest that other types of diagnosis are also unreliable. In one experiment, 27 experienced psychiatrists, all members of a hospital faculty, used a standardized set of 565 statements

30. Pasamanick, Dinitz \& Lefton, Psychiatric Orientation and Its Relation to Diagnosis and Trcatment in a Mental Hospital, 116 AM. J. PsYchIAT. 127 (1959) [hereinafter cited as Pasamanick, et al.].

31. Zubin, supra note 20.

32. Id. at 383 . 
to rate a patient presented to thein in a half-hour filmed interview. ${ }^{33}$ The psychiatrists " . . . were unable to agree as to a patient's diagnosis, prognosis, psychodynamics, the causes of her problems, the feelings she was consciously experiencing or the feelings that were latent (unconscious)." ${ }^{34}$ The authors, noting massive disagreenent, concluded that:

[A] rt far outweighs science when experts in the field of psychiatry try to say what they have discovered in another person. . . . Practitioners of the art disagree with each much more than is conmonly recognized .... Psychiatrists seem to find sufficient strength and self-confidence in consensual validation deriving from what they assume to be and view as shared expert opinion. ("The men who are expert in the field would agree with my judgment."). The findings reported here categorically contradict such a belief. ${ }^{35}$

In a study by Rickles and others, apparently nonpsychotic patients were rated by psychiatrists on an 8-point scale of psychopathology. The reliability of psychopathology ratings among even experienced psychiatrists was found to be quite low, approaching zero. ${ }^{30}$

Nor are psychiatrists very adept at distinguishing between depressed and nondepressed patients. In 1959:

... a Philadelphia psychiatrist and leading depression researcher ... . found himself disturbed by what he called "the low reliability of psychiatric diagnoses of depression." As an experiment he had two skilled psychiatrists diagnose a selected sample of 20 hospital patients. There was a somewhat embarrassing result: Both psychiatrists labeled six of the patients as depressed, but they did not choose the same six. ${ }^{37}$

It is important to understand that psychiatric judgments are not only unreliable with respect to the ultimate diagnoses, but lack consistency even in the perception of the presence, nature, and severity of symptorns. In a study already mentioned above where 17 psychiatrists out of 43 diagnosed a patient as psychotic after all 43 had observed the same film interview, the experimenters concluded that the disagreements were not due solely to differing diagnostic preferences. ${ }^{38}$ Rather, those psychiatrists who reached a diagnosis of schizophrema saw both different and more severe symptoms than other diag.

33. Stoler \& Geertsma, The Consistency of Psychiatrists' Clinical Judgments, 137 J. Nerv. Ment. Dis. 58 (1963).

34. Id. at 64.

35. Id. at 65 (emphasis added).

36. Rickles, Howard, Lipman, Covi, Park \& Uhlenhuth, Differential Reliability in Rating Psychopathology and Global Improvement, $26 \mathrm{~J}$. CuIN. Psychol. 320 (1970).

37. Cherry \& Cherry, The Common Cold of Mental Ailments: Depression, N.Y. Times, Nov. 25, 1973 (Magazine) at 38 [hereinafter cited as Cherry \& Cherry].

38. Katz, Cole \& Lowery, supra note 28. 
nosticians. In the case of another film interview presented by the same experimenters, the differences in diagnostic labels were attributable to disagreements about the level of the patient's apathy and the degree of his distortion of reality, variables that are crucial to the differentiation of psychosis from meurosis. These clinicians were observing the same interview rather than conducting independent examinations; thus, the degree of consistency should have been higher than it would be in actual practice.

Rosensweig observed the same phenomenon after studying the rehability of psychiatric perceptions under very controlled conditions: experienced psychiatrists all observed the same interview (conducted by one of them) of chronic, hospitalized patients. ${ }^{39}$ Nevertheless, there was only moderate agreement among them regarding the presence or degree of a large variety of symptoms.

The preceding studies conclude that psychiatric judginents are not very reliable. ${ }^{40}$ But psychiatrists and judges act as if they were. Pasamamick and his colleagues, after citing other studies which indicate that "psychiatric diagnosis is at present so unreliable as to merit very serious questions when classifymg, treating and studying patient behavior and outcoine,"41 report that despite the unreliability of diagnosis, the length of lospitalization and the types of treatment received are significantly different for patients with different diagnoses. ${ }^{42}$ In other words, differences in diagnosis are not merely semantic quibbles. Conceivably patients with one diagnosis might be discharged or given only tranquilizing medication. Patients with a different diagnosis might be subjected to shock therapy.

The conclusion that psychiatric diagnoses and even perceptions of behavioral symptoms are not very reliable calls into question whether psychiatric opinions are nore rehable than those that laymen might reach. Unfortunately, but perhaps suggestively, we have discovered no studies directly comparing the diagnostic reliability of psychiatrists with that of laymen. ${ }^{43}$ It is clear, lowever, that psychiatrists dis-

39. Rosensweig, Vandenberg, Moore \& Dukay, A Study of the Reliability of the Mental Status Examination, 117 AM. J. Psychiat. 1102, 1104-05 (1961).

40. Even this conclusion may be too conservative. Spitzer and his collaborators have pointed out that most studies of diagnostic reliability (including those discussed herein) overrate "true" reliability by failing to correct the obtained percentage of agreement for chance agreements which may, in certain contexts, be substantial. Spitzer, Colen, Fleiss \& Endicott, Quantification of Agreement in Psychiatric Diagnosis, 17 ARch. Gen. Psychint. 83, 87 (1967)

41. Pasamanick, et al., supra note 30 , at 127.

42. Id.

43. There are a few studies comparing the diagnostic reliability of psychologists and laymen, most of which report no significant difference. E.g., Goldberg, The Effectiveness of Clinicians' Judgments, 23 J. Consulting PsYchol. 25, 33 (1959); 
agree frequently on broad diagnostic judgments; they disagree more often than not on more specific diagnoses; and important consequences flow from the introduction im a judicial setting of one or another of the possible but unreliable "expert" categorizations. When issues of such preeminent importance as the right to liberty are at stake, the available evidence surely does not justify the abrogation of the traditional safeguards afforded by our legal system and the subordination of constitutional rights to a well-meaning but contrary-to-fact belief in the reliability of psychiatric judgments.

\section{B. The Validity of Psychiatric Judgments}

It may be useful to note again that there are at least four kinds of psychiatric judgments that may be relevant in a civil commitment proceeding: is the prospective patient "mentally ill;" is he "dangerous;" does his condition require involuntary lospitalization and treatment; and will involuntary hospitalization and treatment "cure" or benefit the prospective patient? There are very few studies of the validity of psychiatric judgments in the first, third and fourtl areas. There are more studies of the validity of psychiatrie judgments of dangerousness. We will discuss those studies in a moment.

First, lowever, it bears repeating that reliability and validity are not synonymous. A particular judgment is valid if it accurately describes or predicts that which it is intended to describe or predict. ${ }^{44}$

\section{The Validity of Diagnoses}

Although there are comparatively few studies of the validity of psychiatric diagnoses, the studies diseussed above which imdicate that

Plaut \& Crannell, The Ability of the Clinical Psychologist to Discriminate between Drawings by Deteriorated Schizophrenics and Drawings by Normal Subjects, 1 PsyCHOL. RPTS. 153, 157 (1955); Taft, The Ability to Judge People, 52 PsYchol. Bull. 1, 12 (1955); and Walker \& Linden, Varying Degrees of Psychological Sophistication in the Interpretation of Sentence Completion Data, 23 J. CLIN. Psychol. 229, 231 (1967). These and other studies are summarized in ZISKIN, supra note 5, at 147-58. Ziskin notes that in one study, experienced psychologists could distinguish between the drawings of deteriorated schizophrenics and normal subjects 56.7 percent of the time, while college students could do so 56.2 percent of the time. ZIskin, stipra note 5 , at 152. Another study found that experienced psychologists using the Bender-Gestalt test could distinguish brain-damaged patients $60-70$ percent of the time, compared with 57-73 percent for hospital secretaries. Id. at 153. Another study showed that experienced psychologists correctly assessed sentence-coinpletion data 49 percent of the time, while the success rate for engineering students was 42 percent. Id. And still another study concluded "that non-psychologists, at least physical scientists and personnel workers, appear to be more capable of judging others accurately than are either psy. chology students or clinical psychologists." Id. at 154.

44. There are several types of validity: predictive validity, concurrent validity, content validity, and construct validity. For a general discussion of the various types, see CRONBACH, supra note 7, at 104-05. 
such diagnoses are of limited reliability also suggest that they may be of limited validity. And the rate of validity may depend on the use to which these judgments are put. For example, a diagnosis of psychosis may accurately describe qualities the diagnostician perceived in a patient; it may less accurately describe qualities the patient objectively manifested; and it may predict with no accuracy at all whether the patient is dangerous, requires hospitalization, or will benefit from treatment. ${ }^{45}$

Ziskin reviewed the hiterature through 1969 and concluded that

there are few studies providing a scientific basis for drawing conclusions about the validity of diagnosis in general and virtually none in areas concerning their validity for any legally relevant issues, except parole. $^{40}$

Nevertheless, the few studies that do exist suggest that diagnostic validity is quite low.

In a comprehensive research project, Nathan and his co-workers compared the diagnoses given to hospital patients with the symptoms and behaviors recorded by the diagnosticians themselves, thus avoiding the issue of whether a particular symptom or behavior was indeed present. ${ }^{47}$ The authors sought to determine whether the diagnoses followed logically and consistently from the recorded perceptions of behavior, in other words, whether the diagnoses followed the relatively standardized rules for making evaluative judgments based on the presence or absence of various symptoms and beliaviors. Even under these controlled conditions the authors found that diagnoses had only limited validity. They discovered that the diagnosis of psychosis generally was arrived at only when the examiner had recorded the presence of one or more of a small group of symptoms-such as hallucinations, delusions, lack of reality testing, disordered thought processes, or autistic behavior-that are associated with psychosis. On the other hand, more specific diagnoses (sucl as paranoid schizophrenia or hysterical neurosis) were applied even when the examiner had not recorded evidence of one or more symptoms or behaviors supposedly associated with that specific diagnosis. In short, most specific diagnoses do not accurately describe even those symptoms perceived by

45. For a general discussion of the relevance of the concept of validity to psychiatric diagnoses, see Zigler \& Philips, Psychiatric Diagnosis: A Critique, 63 J. ABN, \& Soc. PsYchol. 607, 612 (1961).

46. Ziskin, supra note 5, at 127-28.

47. Nathan, Samaraveera, Andberg \& Patch, Syndromes of Psychosis and Neurosis, A Clinical Validation Study, 19 ARCH. GEN. PsYChIAT. 704 (1968) [hereinafter cited as Nathan, et al.]. 
the examiner, to say nothing of the actual symptoms exhibited by the patient. $^{48}$

Similarly, Zubin cites several studies which conclude that there is little or no relationship between diagnosis and symptomatology; rather there appears to be considerable overlapping of symptoms between diagnostic categories, and within a diagnostic category there is considerable variability of symptomatology. ${ }^{49}$

In another study of diagnostic validity Goldsmith and Mandell selected 34 relatively complete psychodynamic formulations from 336 inpatient records of a psychiatric hospital. ${ }^{.0}$ The formulations described the patients' history, emotions, and motivations in some detail. Each patient originally had been designated as falling within one of seven diagnoses. Psychiatrists and laymen then were asked to study the formulations and to predict the assigned diagnoses. The objective was to determine the extent to which the symptoms and behavior identified in the formulations would enable test participants to reach the same diagnoses. The authors found that the psychiatrists predicted the assigned diagnoses only slightly more often than chance would dictate. More important, there was no significant difference in the accuracy of the diagnostic predictions made by the psychiatrists and those made by laymen. Simce diagnoses are supposed to reflect overt behavior, the study suggests that psychiatrists cannot validly predict behavior from their understanding of the patient's emotional and motivational structure and history. ${ }^{.1}$

48. It will never be possible to assess the "validity" of psychiatric diagnoses until it is first proved that there are such things as "schizophrenia," or "manic-depressive psychosis." On the other hand, if a diagnostic label is merely a short-hand way of describing the presence of certain symptoms, then it should be possible to assess the correspondence between a diagnosis and the presence of symptoms which, by definition, are associated with that diagnosis. Thus, if "schizophrenic" persons are supposed to exhibit symptoms $X, Y$, and $Z$, and if a person with none of those symptoms is diagnosed as "schizophrenic," we could say that particular diagnosis is invalid. It is validity in this more limited sense with which we are concerned here. Even in this qualified sense, however, it is difficult to assess the validity of psychiatric diagnoses; first, because there is no general agreement on the irreducible minimum of symptoms required for each diagnosis, and second, because the symptoms themselves are often so vague or subjective (poor judgment, inappropriate affect, and so forth) that it is impossible to measure the correspondence between such an ephemeral symptom and the diagnostic category. See notes 136-137 infra and accompanying text.

49. Zubin, supra note 20. Cf. Blashfield, An Evaluation of the DSM-II Classification of Schizophrenia, 33 Dissertation ABSTRACTS INT'L, 3927 (1973). Sec also, F. Thorne, Clinical Judgment (1961); Thorne \& Natlan, The General Validity of Official Diagnostic Classifications, 25 J. CLIN. PsYCHOL. 375 (1969).

50. Goldsmith \& Mandell, The Dynamic Formulation: A Critique of a Psy. ehiatric Ritual, 125 Am. J. Psychist. 1738 (1969).

51. Luft, Implicit Hypotheses and Clinical Predictions, 45 J. ABN. Soc. PsYchol. 756 (1950), gave a copy of a diagnostic interview to psychiatrists, psychologists, and physical scieutists (primarily physicists and meteorologists). As summarized by 
On the basis of an exhaustive review of the research literature, Frank observed that "save [for] perhaps the grossest kind of psychotic behavior," there were few if any correlations between diagnoses and patterns of behavior. ${ }^{52} \mathrm{He}$ concluded that "[t]hese data seem to point to the lack of validity of this mode of classifying behavior, and question the [usefulness] of diagnosis." ${ }^{33}$ Another authority, after noting "that many clinicians are unable to make better than chance judginents," concludes that we "can no longer take for granted the vahidity of any clinician's judgment."

\section{The Validity of Predictions of Dangerousness}

Perhaps the most important judgment psychiatrists make is whether or not an individual is "dangerous:"

[A]pproximately 50,000 mentally ill persons per year are predicted to be dangerous and preventively detained . . . . In addition, about $5 \%$. . . of the total mental . . hospital population of the United States ... are kept in maximum security sections on assessment of their potential dangerousness. ${ }^{55}$

There is evidence that the perception of dangerousness is the single most important determinant of judicial decisions to commit individuals or to release patients requesting discharge from a hospital. ${ }^{56}$ Psychiatrists commonly testify at civil commitment proceedings that a given individual is "dangerous" to himself or others. How valid are these predictions? First let us consider the research results on dangerousness to others.

In early 1969 Dershowitz reviewed the few studies in the literature on the prediction of anti-social conduct and concluded:

Ziskin, "Luft found that the clinicians were not superior to the physical scientists in evaluating characteristics [or] . . . in prediction scores." ZISkIN, supra note 5, at 152.

52. Frank, Psychiatric Diagnosis: A Review of Research, 81 J. Gen. PsYchor. 157, 164 (1969) [hereinafter cited as Frank]. See also, Wittenborn \& Lesser, Biographical Factors and Psychiatric Symptoms, 7 J. CLIN. PsYCHOL. 317 (1951).

53. Frank, supra note 52 at 164. See also, Goldberg, Simple Models or Simple Processes: Some Research on Clinical Judgments, 23 AM. PsYchol. 483 (1968).

54. Thorne, Clinical Judgment, in Clnnical Assessment In Counseling and PsYchotherAPX 30-31 (Woody \& Woody, eds. 1972). See ZISkIN, supra note 5, ch. 6 (collecting a substantial body of psychiatric and psychological opinion-not studiesthat psychiatric judgments, including diagnoses, are of low validity).

55. Rubin, Prediction of Dangerousness $I_{n}$ Mentally Ill Criminals, 27 ARCH. Gen. Psychiat. 397 (1972) [hereinafter cited as Rubin].

56. Kunnasaka, Stokes, \& Gupta, Criteria for Involuntary Hospitalization, 26 ArCh. Gen. Psychiat. 399 (1972). For a general analysis of the probleins surrounding attempts to predict dangerousness and for discussion of the concept of preventive detention, see Dershowitz, The Law of Dangerousness: Some Fictions about Predictions, 23 J. Legal ED. 24 (1970); Foote, Comments on Preventive Detention, 23 J. Legal Ed. 48 (1970); von Hirsch, Prediction of Criminal Conduct and Preventive Confinement of Convicted Persons, 21 BUFF. L. REv. 717 (1971-72). 
... that psychiatrists are rather inaccurate predictors-inaccurate in an absolute sense-and even less accurate when compared with other professionals, such as psychologists, social workers and correctional officials and when compared to actuarial devices, such as prediction or experience tables. Even more significant for legal purposes, it seems that psychiatrists are particularly prone to one type of error -overprediction. They tend to predict antisocial conduct im many instances where it would not, in fact, occur. Indeed, our research suggests that for every correct psychiatric prediction of violence, there are numerous erroneous predictions. That is, among every group of inmates presently confined on the basis of psychiatric predictions of violence, there are only a few who would, and many more who would not, actually engage in such conduct if released..$^{67}$

Perhaps the most striking evidence supporting Dershowitz's conclusions comes from the study of the results of "Operation Baxstrom" involving 969 prisoner-patients in New York State who were affected by the Supreme Court's decision in Baxstrom v. Herold. ${ }^{68}$ The Court held that those persons remaining in Department of Corrections hospitals after their prison terms had expired must be released, and committed civilly, if at all. Each of the 969 patients had been detained in maximum-security hospitals because psychiatrists determined that they were mentally ill and too dangerous for release or even for transfer to civil hospitals. Nevertheless, one year after the patients were transferred to civil hospitals, 147 had been discharged to the community and the 702 who remained were found to present no special problems to the hospital staff. Only 7 patients were found to be so difficult to manage or so dangerous as to require recommitment to a Department of Corrections hospital. ${ }^{59}$ Several years later, 27 percent of the patients were living in the community, only 9 had been convicted of a crime (only 2 of felomies), and only 3 percent were in a correctional facility or hospital for the criminally insane. ${ }^{60}$

57. Dershowitz, The Psychiatrist's Power in Civil Commitment: A Knife That Cuts Both Ways, Psychology Today, Feb. 1969, at 47. The author adds that:

One reason for this overprediction is that a psychiatrist almost never learns about his erroneous predictions of violence-for predicted assailants are generally incarcerated and have little opportunity to prove or disprove the prediction; but he always learns about his erroneous predictions of nonviolenceoften from newspaper headlines announcing the crime. This higher visibility of erroneous predictions of nonviolence inclines him, whether consciously or unconsciously, to overpredict violent behavior.

Id. at 47 .

58. 383 U.S. 107 (1966).

59. Hunt \& Wiley, Operation Baxstrom After One Year, 124 AM. J. Psycinat. 974 (1968). The follow up figures after one year reflect a total of less than 969 since they do not include 24 deaths, 10 transfers, 62 convalesents, and 24 miscellaneous dis. positions.

60. Steadman \& Keveles, The Community Adjustment and Criminal Activity of the Baxstrom Patients: 1966-70, 129 AM. J. PsYCHIAT. 309 (1972). The authors also 
As one of the authors has written elsewhere:

In statistical terms, Operation Baxstrom tells us that psychiatric predictions are incredibly inaccurate. In human terms, it tells us that but for a Supreme Court decision, nearly 1,000 human beings would have hived much of their lives behind bars, without grounds privileges, without home visits, without even the limited amenities available to civil patients, all because a few psychiatrists, in their considered opinion, thought they were dangerous and no one asked for proof. ${ }^{01}$

Another recent study, ${ }^{62}$ described by one observer as "the most extensive study to date on the prediction ... of dangerousness in criminal offenders," at least five mental health professionals, including two or more psychiatrists, was asked to conduct unusually thorough clinical examinations of individuals who had been convicted previously of serious assaultive crimes (often sexual in nature), assigned to special treatment programs after conviction, and who were then eligible for release. Based upon the examinations, extensive case histories, and the results of psychological tests, the team attempted to predict which individuals again would commit assaultive crimes if released. These predictions of dangerousness were made prior to the court hearings at which the ultimate release decisions were made. Of 49 patients considered by the evaluating team to be dangerous and therefore not recommended for release, but who nevertheless were released after a court hearing, 65 percent had not been found to have committed a violent crime within five years of returning to the community. In other words, twothirds of those released despite predictions of dangerousness by the professional team did not in fact turn out to be dangerous. ${ }^{64}$

provide evidence that it is difficult to predict arrests and convictions. Indeed, they suggest that reliable predictions of dangerousness cannot be made with the present state of knowledge, because there are no solid research findings regarding the factors that accurately predict dangerous behavior.

61. Ennis, The Rights of Mental Patients, in THE Rights of AMERICANS 487 (Dorsen ed. 1970). The Baxstrom studies show that psychiatric judgments that were intended to be humane nevertheless subjected several hundred people to an unnecessary loss of liberty. Similarly, other studies have shown that imcompetence-to-stand-trial judgments by psychiatrists often harm rather than help crininal defendants. See McGarry, The Fate of Psychotic Offenders Returned For Trial, 127 AM. J. Psychiat. 1181 (1971).

62. Kozol, Boucher, \& Garofalo, The Diagnosis and Treatment of Dangerousness, 18 CRIME \& DELINQUENCY 371 (1972) [hereinafter cited as Kozol].

63. Monahan, Dangerous Offenders: A Critique of Kozol, et al., 19 CRIME \& DeLINQuenCY 418 (1973) (a letter from John Monahan to the Editor).

64. Not only did Kozol's patient sample consist only of known assaultive ofenders, but most of them had assaulted young victims. As the authors recognize, "the person who would assault a relatively helpless victim ... must have an extremely strong urge to do violence." Kozol, supra note 62, at 378. That factor, which should increase the rate of correct prediction, is not usually present when predictions 
Furthermore, as the authors of this study note:

The difficulty involved in predicting dangerousness is immeasurably increased when the subject has never actually performed an assaultive act . . . . We submit that to properly assess indications of possible dangerousness in the absence of an actual instance of dangerous acting out requires the highest degree of psychiatric expertise and may well exceed the present limits of our knowledge . . . . No one can predict dangerous behavior in an individual with no history of dangerous acting out..$^{\mathrm{s}}$

One psychiatrist has noted that there is no empirical support for the belief that psychiatrists can predict dangerous behavior. ${ }^{30}$ To the contrary, even with "the most careful, painstaking, laborious, and lengthy clinical approach to the prediction of dangerousness, false positives may be at a minimum of 60 to $70 \% . "{ }^{67}$ In other words, even under controlled conditions, at least 60 to 70 percent of the people whom psychiatrists judge to be dangerous may, in fact, be harmless. Similarly another psychiatrist acknowledges that psychiatrists "cannot predict with even reasonable certainty that an imdividual will be dangerous to himself or others."

of dangerousness are made. This suggests that the high error rate of 65 percent is much lower than the rate of error that would be expected in general practice. On the other hand, the error rate of 65 percent is based on a sample of borderline cases which may not be representative of all the predictions of dangerousness made by these psychiatrists. A somewhat lower error rate is possible in those cases where the non-psychiatric decision-maker would agree with the psychiatrist, but of course such a lower erJor rate is not then attributable to any special ability of the psychiatrist.

65. Kozol, supra note 62, at 384 (emphasis added). The authors note that only 8 percent of the offenders recommeuded for discharge (as being nondangerous) were recidivists. This suggested to them that mental health professionals may be able to predict nondangerous behavior. However, the fact that predictions of nondangerousness were wrong only 8 percent of the time may simply be a function of the low base rate of violent behavior. That is, if $90-99$ percent of any given population will not engage in violent behavior, predictions of individual nonviolence within that population will uecessarily be generally accurate. See Monahan, supra note 63; Kozol, Boucher, \& Garofalo, Dangerousness, 19 CRIME \& DeLinquenCY 554 (1973) (a letter to the editor).

66. Rubin, supra note 55, at $397-98$ citing Kozol, Boucher, \& Garofalo, The Diagnosis of Dangerousness, (a paper read to the annual meeting of the American Psychiatric Association, San Fraucisco, May 13, 1970).

67. Rubin, supra note 55, at 397-98. Cocozza \& Steadman, Some Refinements in the Measurement and Prediction of Dangerous Behavior, 131 AM. J. PSYCHIAT. 1012 (1974).

68. Usdin, Broader Aspects of Dangerousness in The Clinicar Evaluation of the Dangerousness of the Mentally Ill 43 (J. Rappeport ed. 1967).

Regarding the abihty of psychological tests to measure "dangerousness", sec Megaree, Tize Prediction of Violence with Psychological Tests, in 2 CURRENT TOPICs in Clinical and Community Psychology 97 (C. Spielberger ed. 1970) which concludes:

Thus far no structured or projective test scale has been derived which, when used alone, will predict violence in the individual case in a satisfactory manner. Indeed, none has been developed which will adequately postdict, let alone predict, violent behavior.

Id. at 145 . 
Still another study found that only five of 1,630 parolees ( .31 percent, or less than one-third of one percent) identified by the California Department of Corrections at the time of release as "Potentially Aggressive" (based on a history of aggressive behavior and psychiatric predictions) actually committed known violent crimes after release, as compared with .28 percent of those parolees $(17$ of 6,082$)$ who were not predicted to be potentially aggressive. ${ }^{69}$ On the basis of their studies and review of the literature, the authors concluded that, even for individuals known to have committed a violent act,

The best prediction available today . . . is that any particular member of that set will not become violent . . . There has been no successful attempt to identify, within either of the offender groups, a sub-class whose members have a greater-than-even chance of engaging again in an assaultive act. ${ }^{70}$

They also add that:

Confidence in the ability to predict violence serves to legitimate intrusive types of social control. Our demonstration of the futility of such prediction should have consequences as great for the protection of individual hiberty as the demonstration of the utility of violence prediction would have for the protection of society. ${ }^{71}$

Monahan summarized his review of the most recent literature on the prediction of violence as follows:

The conclusion to emerge most strikingly from these studies is the great degree to which violence is overpredicted .... O Of those predicted to be dangerous, between $65 \%$ and $95 \%$ are false positivespeople who will not, in fact, commit a dangerous act. Indeed, the literature has been consistent on this point ever since Pinel took the chains off the supposedly dangerous mental patients at $\mathrm{La}$ Bicetre in 1792 , and the resulting lack of violence gave lie to the psychiatric predictions which justified their restraint. Violence is vastly overpredicted whether simple behavioral indicators are used or sophisticated

69. Wenk, Robison \& Sineth, Can Violence be Predicted? 18 CRIME \& DeLINQUENCY 393 (1972).

70. Id. at 394. The authors report two additional studies. In the first, a violence prediction scale was constructed from a number of seemingly relevant items, and was administered to a large number of parolees. Yet, only 14 percent of the exoffenders predicted by the instrument to be dangerous violated parole by committing a (known) violent, or potentially violent act-as compared to a 5 percent rate of violent acts for the parolees predicted to be nondangerous. In the second study, despite the use of "elaborate case histories, current measures of mental and emotional functioning, and professional diagnosis," it was found to be impossible to develop a classification scheme for identifying which of over 4,000 California Youth Authority wards on parole would commit a violent, recidivistic offense. Indeed, no single predictive criterion or "item" was found to produce accurate predictions in more than one out of every 20 cases.

71. Id. at 402. 
multi-variate analyses are employed, and whether psychological tests are administered or thorough psychiatric examinations are performed. It is also noteworthy that the population used . . . [in recent] studies was highly selective and biased toward positive results -primarily convicted offenders, "sexual psychopaths," and adjudicated delinquents. The fact that even in these groups, with higher base-rates for violence than the general population violence cannot be validly predicted bodes very poorly for predicting violence among those who have not committed a criminal act. ${ }^{72}$

Finally, there is no support in the literature for the popularly held notion that the mentally ill are more dangerous, as a group, than the general population; ${ }^{73}$ or for any belief that the presence of a psychiatric disturbance, per se, makes the prediction of violence easier and more accurate than would otherwise be the case. ${ }^{74}$

The studies discussed thus far are, for the most part, studies of the validity of predictions of danger to others. There are, in addition, numerous studies of the validity of predictions of danger to self. Writing in 1972, Murphy concluded that "prediction of the infrequent event of suicide is poor. It would be very much poorer in a population unselected for risk. The development of predictive tools of high accuracy has not yet been achieved, not even for populations with high risk of suicide (of which suicide attempters are but one example)."

An even more recent and comprehensive review of the literature by Greenberg concludes that "a method for distinguishing persons who will suicide from those who will not with a measure of accuracy sufficiently high to permit its use im psychiatric commitinents simply does not exist at present."'7o

72. Monahan, The Prediction and Prevention of Violence, in Procegdinos op the PaCific Northwest Conferenoe on Vlolence and Crimtinal Justice (Issaquah, Washington, Dec. 6-8, 1973) (to be published) [hereinafter cited as Monahan].

73. See Gulevich \& Boume, Mental Illness and Violence, in V1OLENCE AND the Struggle for Existence 309 (D. Daniels, M. Gilula, \& F. Ochberg eds. 1970); and the authorities cited infra at note 145 .

74. The Pennsylvania Task Force on Commitment Procedures concluded that "since the capacity to predict dangerous conduct is no greater in the case of mentally ill persons than others, preventive detention is no more justified in the case of mental illness than elsewhere." Commonwealth of Pennsylvania, Task Force IN COMmTtMent Procedures, Dep'T of Public Welfare (1972), cited in J. Monahan, Dangerousness and Civil Commitment 4 (Invited Testimony Before the California Assembly Select Committee on Mentally Disordered Criminal Offenders. Patton, California, Dec. 13, 1973).

75. Murphy, Clinical Identification of Suicidal Risk, 27 Arch. Gen. Psychist. 356, 357 (1972).

76. Greenberg, Psychiatric Commitments to Prevent Suicide: Social Science and Social Policy at 131 (paging of prepublication draft) (to be published in the New York University Law Review, May or June, 1974). 


\section{The Validity of Predictions of the Need for \\ Hospitalization and Treatment}

Psychiatrists frequently predict whether a person's condition requires hospitalization or treatment. That is, they often predict whether a person will be able to "get along" outside a hospital. Again, there are very few studies of the validity of such predictions. It is difficult to conduct such studies because once the psychiatrist predicts that the individual will not be able to get along in the community the individual is usually hospitalized, denying researchers the opportunity to determine whether the prediction was right or wrong.

In one relevant study, Rappeport, Lassen, and Gruenwald studied 73 patients who requested court hearings to obtain release from a psychiatric hospital. ${ }^{77}$ Their psychiatrists felt they were not suitable for release. Of the 73,26 were released by the courts-despite the objections of their psychiatrists-and 47 were remanded to the hospital. Twelve of the 47 subsequently escaped. The investigation studied the community adjustment of these 38 individuals after at least one year. Notably, 44 percent of the court-released and 42 percent of the escaped patients nrade a satisfactory adjustment to the community (they had not been in serious trouble with the law, had not been rehospitalized, and were caring for themselves). Of equal significance, in neither group did any serious anti-social behavior occur, although a number of the patients who did not adjust were involved in minor accidents or crimes. Since these rates of adjustment compared favorably with those obtained in studies of patients released on the recominendation of psychiatrists, and since the courts here acted contrary to the opinions of psychiatrists in what were presumably difficult cases, the investigators concluded that ". . . the courts may be considered [to have] a better prediction rate [than psychiatrists] since they released patients that otherwise would not have been released at that time."78 The reasons for this outcome suggested by the authors-psychiatrists nay have less tolerance for deviant behavior and nay require greater certainty of community adjustment than judges-are examined in Part II below. ${ }^{79}$

There are also a few studies that are less directly on point but are still suggestive. The details vary froin study to study, but the es-

77. Rappeport, Lassen \& Gruenwald, Evaluations and Follow-up of State Hospital Patients Who Had Sanity Hearings, 118 AM. J. PsYchus. 1079 (1962).

78. Id. at 1083. See also, Zwerling \& Wilder, An Evaluation of the Applicability of the Day Hospital in Treatment of Acutely Disturbed Patients, 2 IsRaEl ANNALS of Psychist. 162 (1964). Cf. Livermore, Malmquist, \& Meehl, On the Justifications for Civil Commitment, 117 U. Pa. L. Rev. 75, 85, n.29 (1968) (regarding release or elopement against medical advice) [hereinafter cited as Livermore, et al.].

79. See text àccompanying notes 84-147. 
sential points are similar. In each study individuals who had been examined in a hospital admission ward and found to require full-time hospitalization and treatment were randomly divided into two groups. One group was hospitalized and the other was treated in the cominunity or in a day hospital on an outpatient basis. Over a substantial period of time, only a few of the community patients failed to get along in the community and had to be hospitalized. In fact, the community patients recovered faster than the hospitalized patients (and cost the state half as much money). ${ }^{80}$

\section{The Validity of Predictions of the Effect of Hospitalization and Treatment}

Whether a prospective patient will respond favorably or unfavorably to hospitalization and treatment should be a central issue in every commitment proceeding. Unfortunately, it is not. Once again we find that there are very few studies of the validity of psychiatric predictions of the probable outcome (the "prognosis") of hospitalization and treatment.

80. See, e.g., Langsley, Pittman, Machotka \& Flomenhaft, Family Crisis Therapy Results and Implications, 7 FAMILY Process 145 (1968). A very recent study questions the assumptions underlying commitment of mentally ill persons to mental hospitals. Reding \& Maguire, Nonsegregated Acute Psychiatric Admissions to General Hospitals-Continuity of Care Within the Community Hospital, 289 N. ENo. J. MED. 185 (1973). Over a four-year period a total of 344 patients were admitted as psychiatric emergencies to the nonpsychiatric units of the three general hospitals of a New York County. Forty percent of the patients were diagnosed as schizophrenic or paranoid, 25 percent as depressed or suicidal, and 8 percent as personality disorders involving violent behavior at home. Physical restraints and electroconvulsive therapy were not used. The median length of hospitalization ranged from 6.5 days for one group of patients to 8.5 days for another, compared with a median stay in psychiatric units of general hospitals in New York of 15-24 days, and in New York State Mental Hospitals of 51 days. Of the 344 admissions there was not one suicidal or honicidal attempt in over 4,000 days of acute psychiatric hospitalization. Id. at 187. The researchers found that "[t]he atmosphere of the nonpsychiatric general-hospital unit seemed to have a soothing or tranquilizing effect on patients with acute psychiatric illness." Id. The researchers concluded that "this effect is partly accounted for by a constant negative reinforcement of antisocial behavior, in contrast to what prevails in psychiatric wards, where patients are expected to exhibit disturbed behavior and where agitated behavior in one patient leads to agitation in another." Id. The researchers also concluded that admission of such patients to general hospitals rather than to mental hospitals "scems to shorten the length of hospitalization" and "seem[s] to offer a satisfactory and less costly alternative to the traditional forms of psychiatric hospitalization." Id. at 188. This study suggests that predictions that allegedly mentally ill people require commitment to a mental hospital are often erroneous.

A paper titled Alternatives to the Hospital-A Controlled Study, by Leonard I. Stein, Mary Ann Test, and Arnold J. Marx, presented at the meeting of the American Psychiatric Association in Detroit, Michigan on May 9, 1974, describes another random hospital/community study. The authors concluded that community treatment is a feasible alternative for patients who would otherwise have been hospitalized, that community treatment virtually eliminates the need for hospitalization, and that community treatment increases the productive functioning of the community group. 
Robbins and Guze surveyed the literature concerning the validity of clinicians' judgments of the prognosis of schizophrenic patients. ${ }^{81}$ They found considerable variations between the predicted prognoses and the actual outcomes of treatment. In practice, patients who received a poor prognosis did poorly as infrequently as 55 percent of the time in one study and as frequently as 91 percent of the time in another. In contrast, patients with a good prognosis did well as frequently as 83 percent of the time in one study and as infrequently as 36 percent in another. ${ }^{22}$

Other investigations showed that psychiatrists accurately predicted the beneficial or nonbeneficial effect of electro-shock therapy for several hundred patients only 41 percent of the time. ${ }^{83}$ In other words, their predictions would have been more valid if they had been based on the flip of a coin.

The studies discussed in Part I indicate that psychiatrists often disagree in their judgments and that even where they do agree those judgments-especially predictive judgments-are often wrong. In particular, psychiatric predictions that an individual is dangerous are usually wrong. Furthermore, perceptions of symptoms and behavior vary dramatically among examining psychiatrists and for some diagnostic categories there is little relationship between the syniptoms and behavior perceived by the psychiatrist and the eventual diagnosis. For specific diagnostic categories, there is little evidence that the symptoms and behavior perceived by the psychiatrist were actually exhibited by the patient. Accordingly, a diagnosis often suggests that a patient has exhibited certain symptoms or behavior which he or she did not in fact exhibit. In short, diagnoses often convey more maccurate than accurate information about patients.

\section{II}

\section{Reasons Why Psychtatric Judgments are Unreliable AND INVALID}

Before discussing the specific reasons why psychiatric judgenents are unreliable and imvalid it is necessary to recognize a more general

81. Robbins \& Guze, Establishment of Diagnostic Validity In Psychiatric Illness: Its Application to Sclizophrenia, 126 AM. J. PsYchrat. 983 (1970).

82. A psychiatric prognosis can be a self-fulfilling prophecy because only those patients with a good prognosis arc likely to receive the aid of scarce psychotherapeutic resources.

83. Wittman, A Scale for Measuring Prognosis in Schizophrenic Patients, 4 ELGIN PAPERS 20-33 (1941), cited in ZISKIN, supra note 5, at 132-33; Wittman \& Steinberg, Follow-up of an Objective Evaluation of Progress In Dementia Praecox and Manic-Depressive Psychosis, 5 ELGIN PAPERS 216-27 (1944); cited and discussed in ZIskIN, supra note 5, at 132-33. 
problem: individual psychiatrists are not given any opportunity to learn from their mistakes. Goldberg, for example, points out that clinicians rarely get feedback on the accuracy of their judgments. ${ }^{84}$ They may believe their judgments are reliable and valid, but they have no systeinatic way of testing that belief. ${ }^{85}$ For "[u]nlike other specialties, psychiatry lacks adequate statistics and followups, because psychiatrists have not seriously attempted to check on their methods and results in the way other medical doctors regard as their scientific duty." a result, very little of what psychiatrists think they are able to do "can be adequately validated." 87 One psychiatrist has acknowledged that the absence of a self-corrective inechanism means that in many cases, "the diagnosis of psychosis becomes almost a matter of chance. It is dependent on the training, experience and personal philosophies of the psychiatrist who examines the [person] and the circumstances under which the [person] is examined." 88

Although the specific reasons why psychiatric judgments and predictions are unreliable and invalid are varied, many of them can be grouped under six broad and occasionally overlapping headings: 1) orientation and training, 2) context, 3) time, 4) class and culture, 5) personal bias, and 6) inadequacies of the diagnostic system and ambiguity of psychiatric data. Finally, there are additional reasons for the inaccuracy of psychiatric predictions of dangerousness.

\section{A. Orientation and Training}

It has been suggested that psychiatrists are prone to diagnose mental illness and to perceive symptoms in ambiguous behavior because they are trained in medical school that it is safer to suspect illness and be wrong, than to reject illness and be wrong. ${ }^{80}$ In other

84. Goldberg, supra note 53, at 484 .

85. See Chapman \& Chapman, Genesis of Popular but Erroneous Psychodiagnostic Observations, 72 J. ABNORM. PSYCHOL. 193 (1967).

86. Schmideberg, The Promise of Psychiatry: Hopes and Disillusionment, 57 Nw. U.L. REv. 19, 21 (1962) [heremafter cited as Schmideberg].

87. Id.

88. Halleck, A Critique of Current Psychiatric Roles In The Legal Process, 1966 Wisc. L. Rev. 379, 393. See also, Baur, Legal Responsibility and Mental Itlness, 57 Nw. U.L. Rev. 12, 14-17 (1962); Diamond \& Louisell, The Psychiatrist as an Expert Witness: Some Ruminations and Speculations, 63 MrcH. L. REv. 1335, 1341 (1965) [hereinafter cited as Diamond \& Louisell]; Sadoff, Psychiatry Pleads Guilty, 51 A.B.A.J. 48,49 (1965); Schmideberg, supra note 86.

89. E.g., Leifer, The Competence of the Psychiatrist in the Determination of Incompetency: A Skeptical Inquiry into the Courtrooin Functions of Psychiatrists, 14 SyRACUSE L. REv. 564, 573 (1963); Livermore, et. al., supra note 78, at 77; Shah, Crime and Mental Illness: Some Problems in Defining and Labeling Deviant Behavior, 57 Mental Hygiene 21 (1969); Temerlin, Suggestion Effects in Psychiatric Diagnosis, 147 J. Nerv. Ment. Dis. 349 (1968). 
words, "being a mental health professional may constitute a set to perceive mental illness. . . ."90

In addition, each school of psychiatry has a different view of what mental illness is, how it is caused, and how it should be treated. Substantial evidence suggests that psychiatric judgments are strongly influenced by these different schools of thought and training. Pasamanick, Dinitz, and Lefton, for example, inferred from their findings that:

... despite their protestations that their point of view is always the individual patient, clinicians in fact may be so committed to a particular school of psychiatric thought that the patient's diagnosis and treatment is largely predetermined. Clinicians ... may be selectively perceiving only those characteristics and attributes of their patients which are relevant to their own pre-conceived system of thought. As a consequence, they may be overlooking other patient characteristics which would be considered crucial by colleagues who are otherwise committed . . . .91

90. Temerlin, Diagnostic Bias in Community Mental Health, 6 CoMMUNITY Mental Healith J. 110, 115 (1970) [hereinafter cited as Temerlin]. In one study two groups of graduate students in clinical psychology viewed a taped interview and were asked to evaluate the interviewee. One group represented the behaviorist and the other the psychoanalytic orientation. Behaviorists are trained to describe carefully the behavior an individual manifests bnt to refrain from making any judgments or inferences about that individual or his behavior; analysts are more willing to make such speculations. Half the clinicians were told the interviewee in the film was a "job applicant" and half were told he was a "patient." It was found that the behaviorists rated the subject approximately the same (on an adjustment rating scale) regardless of the "set;" the analysts, on the other hand, agreed with the behaviorists on the adjustment of the "job applicant" but saw the "patient" as a much more disturbed person. Langer and Abelson, A Patient By Any Other Name . . . Clinician Group Difference In Labeling Bias, (unpublished study on file at New York Civil Liberties Union, 84 Fifth Avenue, New York, N.Y. 10011, and at the Department of Psychology, Yale University, New Haven, Conn.) isee generally, Kanfer and Saslow, Behavioral Analysis: An Alternative To Diagnostic Classification, 12 ARCH. Gen. Psychnat. 529 (1965).

91. Pasamanick, et al., supra note 30, at 131. See also Grosz \& Grossman, The Sources of Observer Variation and Bias in Clinical Judgments: I. The Item of Psychiatric History, 138 J. NeRv. MeNr. Dis. 105, 111 (1964); Nathan, Thirty-two Observers and One Patient: A Study of Diagnostic Reliability, 25 J. CLIN. Psychol. 9 (1969). For evidence that ideas about the same diagnostic category may vary significantly with the diagnostician's professional identity, theoretical orientation, and employment setting, see Fitzgibbons \& Sliearn, Concepts of Schizophrenia Among Mental Health Professionals, 38 J. Consurt. \& Cin. PsYchol. 288 (1972).

In a recent study by Taylor, Gaztanaga, and Abrams, Manic-Depressive Illness and Acute Schizophrenia: A Clinical, Family History, and Treatment-Response Study, 131 AM. J. PsYCHIAT. 678 (1974), 26 consecutive patients who liad been admitted to an inpatient psychiatric unit of a general hospital with a diagnosis of "acute schizophrenia" were carefully re-examined by the authors to determine whether these individuals indeed met the clinical criteria for the diagnosis of acnte schizophrema. Only one of the 26 patients in fact met the criteria. The 25 other patients were all re-classified with non-schizophrenic diagnoses. Commenting on the findings another psychiatrist points out that there are significant (mis) treatment consequences of sucl1 faulty diagnoses, and lie adds that "[t]lere is an unusual readiness to diagnose (or misdiagnose) schizophrenia in the 


\section{B. Context}

If upon entering a room one notices a book in a wastebasket, it is reasonable to assume it is not a valuable book. But seeing the same book in a locked book case gives rise to an entirely different opinion as to its value. Similarly, a person dressed in normal clothing and sittimg in his living room creates one impression, while the same person dressed in a hospital robe and slippers and sitting on a bench in a hospital corridor creates a much different impression. It should therefore come as no surprise to learn that diagnosis is often influenced by the setting in which a person is observed, with impatient settings disposing clinicians toward a diagnosis of psychosis. ${ }^{02}$

Other factors, in addition to the place of examination and appearance of the subject, may influence diagnosis. To illustrate, the effect of "suggestion" or "set" was examined in a study in which an actor portrayed a healthy man while talking about himself in a diagnostic interview with a clinician. ${ }^{93}$ The interview was recorded and played to groups of a) graduate students in climical psychology, b) psychiatrists, c) law students, and d) undergraduates. Before playing the tape, however, a prestige figure-a different person for each group -told the groups that the interview was interesting because the subject "looked neurotic but actually is quite psychotic." As a control four comparable groups heard the taped interview but were given no prestige suggestion for "psychosis." After hearing the tape, the groups were asked to assign the interviewee to one of 30 specified diagnostic categories. None of the control groups diagnosed the subject as psychotic, and the majority diagnosed him as healthy. By contrast, 60 percent of the psychiatrists, 30 percent of the undergraduates, 28 percent of the psychologists, 17 percent of the law students, and 11 percent of the graduate psychology students diagnosed psychosis. ${ }^{.44}$ The authors conclude that prestige suggestion imfluences diagnosis, and that an initial diagnosis "may have a profound effect" upon a sub-

United States because insufficient attention is paid to the basic steps in psychiatric history taking and examination procedures." Straker, Editorial: Schizophrenia and Psychiatric Diagnoses, 131 AM. J. Psychiat. 693 (1974).

92. See, e.g., Babigian, Gardner, Miles \& Romano, Diagnostic Consistency and Change in a Follow-up Study of 1215 Patients, 121 Am. J. Psychist. 895 (1965).

93. Temerlin, supra note 90.

94. The interesting differences among the groups in the percentage of psychotic diagnoses are doubtless due to a number of different factors. One such factor might be the perception of the prestige fignre; the law students, for example, may have felt the criminal law professor assigned as their prestige figure was speaking outside his area of expertise when he suggested the subject was psychotic.

The important finding for our purposes is that while some members of every group, especially the psychiatrists, made diagnoses of psychosis, none of the comparable control groups did so. 
sequent diagnosis by influencing "interpersonal perception, whether or not the [initial] diagnostic label refers to a disease which actually exists." ${ }^{\prime 25}$ In other words, clinicians often perceive what they expect to perceive and the impact of suggestion on clinical perception may be profound.

In a study of pseudo-patients, eight sane individuals feigning one symptom of schizophrenia were admitted to various mental hospitals with that diagnosis. ${ }^{96}$ Rosenhan found that even though immediately after admission the pseudo-patients ceased displaying that symptom and behaved normally,

once a person is designated abnormal, all of his other behaviors and characteristics are colored by that label. Indeed, that label is so powerful that many of the pseudo-patient's normal behaviors were overlooked entirely or profoundly misinterpreted. ${ }^{97}$

For example, when several of the pseudo-patients took notes of their experiences, that activity was noted in three of their records as "an aspect of their pathological behavior."98 The purpose of Rosenhan's study was to determine whether "the salient characteristics that lead to diagnoses reside in the patients themselves or in the environment and contexts in which observers find them." 99 Although the pseudopatients related absolutely normal life histories, Rosenhan found that "diagnoses were in no way affected by the relative health of the circumstances of a pseudo-patient's life. Rather, the reverse occurred: the perception of his circumstances was shaped entirely by the diagnosis." 100 Other studies focusing on the importance of context likewise conclude that "the initial set with which the interviewer begins the interview has considerable effect upon the outcome."101 For example "[i]nterviewers given different sets about interviewees (i.e., that interviewees are cold or warm) perceive interviewees differentlyeven after 30 minutes of interview time."102

\section{Time}

Since even "normal" people speak and behave differently froun one day to the next, it is no less natural for an allegedly mentally ill

95. Temerlin, supra note 90 , at 116 .

96. Rosenhan, On Being Sane In Insane Places, 179 ScIENce 250 (1973) [hereinafter cited as Rosenhan].

97. Id. at 253.

98. Id.

99. Id. at 251.

100. Id. at 253. See also Rubin, supra note 55, at 405.

101. Huguenard, Sager \& Ferguson, Interview Time, Interview Set, and Interview Outcome, 31 Percept. \& Mot. SkILLs, 831, 834 (1970).

102. Id. at 834-36. See also Asch, Forming Impressions of Personality, $41 \mathrm{~J}$. ABNORM. \& SOC. PSYCHOL. 258 (1946). 
individual to appear agitated one day and composed the next. Consequently, the timing of a prospective patient's examination may substantially influence the diagnosis he or she is given. In his 1967 review of studies, Zubin found that the consistency over time of specific diagnoses of nonorganio conditions is quite low, and that even the "broad diagnostic categories appear to display a low order of consistency [about 50 percent] over time." 103 In a related study Edelman found that diagnostic impressions change by a fourth interview-therapy session about 25 percent of the time. ${ }^{104} \mathrm{He}$ also noted that:

The typical procedure for establishing a diagnosis is a single unstandardized interview, the results of which may be augmented by psychological testing. An implicit assumption of this procedure is that interviewee behavior has been adequately sampled in the allotted time span and that the interviewee is sufficiently motivated to reveal all pertinent information. Yet, there are numerous studies which indicate that interviewee behavior is mediated by complex process variables suggesting that such assumptions may not always be justified. ${ }^{105}$

In other words, even if a patient's behavior is consistent over time, different aspects of that behavior may be observed at different times. ${ }^{100}$

In addition, the limited amount of time usually available for a psychiatric evaluation may combime with the psychiatrist's "set" to perceive mental illness, thus resulting in overpredictions of disturbance. For example, when there is only limited time to examine a patient who is allegedly dangerous, the psychiatrist is likely to search for, and find, signs of dangerousness such as aggressive fantasies. He is not nearly so apt, however, to be attentive to evidence of nondangerousness, such as a history of good impulse control.

\section{Class and Culture}

There is considerable evidence that psychiatric judgments are strongly influenced by the socio-economic backgrounds of the clinician

103. Zubin, supra note 20, at 386. See also, Hunt, Wittson \& Hunt, $A$ Theoretical and Practical Analysis of the Diagnostic Process, in Current Problems in Psychiatric Diagnosis 53 (P. Hoch \& J. Zubin eds. 1953).

104. Edelman, Intra-therapist Diagnostic Reliability, 25 J. CiIN. PsYchol. 394 (1969).

105. Id. at 395. To the extent that psychiatric diagnoses vary over relatively brief periods of time, a diagnosis at a given moment, however reliable, becomes that much less meaningful for the behavior the individual is exhibiting at that time may be very much a function of the particular situation. See the discussion of "meaningfulness" in Part III infra.

106. See Ward, Beck, Mendelson, Mock \& Erbaugh, The Psychiatric Nomenclature: Reasons for Disagreement, 7 ARCH, GEN, PSYchIAT. 198 (1962) [hereinafter citẹ̦ as Ward, et al.]. 
and patient. Philips and Draguns reviewed the literature from 1966 to 1969 and concluded:

... The influence of the client's socio-economic class in facilitating the attribution of some, and impeding the application of other, nosological designations is particularly well documented ... [T]he findings converge in suggesting social distance as the mediating variable. Across socio-economic or other subcultural lines, the middle class diagnostician is prone to assign categories of severe psychopathology . . . . ${ }^{107}$

In a controlled experiment, Lee and Temerlin found that the diagnoses of psychiatric residents were highly influenced by the imagined socio-economic history of the patient (and by the perceived diagnoses of other, prestigious psychiatrists) independent of the clinical picture presented. A lower socio-economic history biased diagnosis toward greater illness and poorer prognosis. ${ }^{108}$ Similarly, according to studies conducted by Ordway, clinicians may be influenced to conclude that lower socio-economic class individuals are dangerous because such individuals are presumed to be impulsive and therefore more prone to violence. ${ }^{109}$

Different cultural backgrounds may also have profound effects on clinicians' perceptions. In one study, 23 patients were interviewed by

107. Phillips \& Draguns, Classification of the Behavior Disorders, 22 ANN. Rev. PsYCHOL. 447, 467 (1971).

108. Lee \& Temerlin, Social Class, Diagnosis, and Prognosis for Psychotherapy. 7 Psychotherapy: Theory, Research \& Prac. 181 (1970). See also Garfield, Weiss \& Pollack, Effects of the Child's Social Class on School Counselor's Decision Making, 20 J. Counsed. PsYchol. 166 (1973); Harrison, McDermott, Wilson \& Sclurager, Social Class and Mental Illness in Children: Chance of Treatment, 13 ARCH. GEN. Psychiat. 411 (1965); Harrison, McDermott \& Showerman, Social Status and Child Psychiatric Practice: The Influence of the Clinician's Socio-Economic Origin, 127 AM. J. PsychuAr. 652 (1970); Routh \& King, Social Class Bias in Clinical Judgment, 38 J. Consult. \& Clin. Psychol. 202 (1972); Stein, Greene \& Stone, Therapists Attitude as Influenced by A-B Therapist Type, Patient Diagnosis, and Social Class, 39 J. Consult. \& Clin. Psychol. 301 (1972). For the effect of race and sex see Allon, Sex, Race, Socio-Economic Status, Social Mobility, and ProcessReactive Ratings of Schizophrenics, 153 J. NeRv. MENT. DIs. 343 (1971); Gross, Herbert, Knatterud \& Donner, The Effect of Race and Sex on the Variation of Diagnosis and Disposition in a Psychiatric Emergency Room, 148 J. NERV. MENT. Dis. 638 (1969). Similar findings have been obtained in the studies of the influence of climician bias on psychological test interpretation. See, e.g., Haase, The Role of Socioeconomic Class in Examiner Bias, in MeNTAL Health of THE POoR 241-47 (F. Riessman, J. Cohen, and A. Pearl, eds. 1964); Levy \& Kahn, Interpreter Bias on the Rorschach Test as a Function of Patient's Socio-economic Status, 34 J. ProJ. Techs. Pers. AssessMent 106 (1970); Trachtman, Socio-economic Class Bias in Rorschach Diagnosis: Contributing Psychological Attributes of the Clinician, 35 J. PERS. AssessMENT 229 (1971).

109. Ordway, Experiences in Evaluating Dangerousness in Private Practice and in a Court Clinic, in The Clinical Evaluation of the Dangerousness of the Mentally Ill 35 (J. Rappeport, ed. 1967). 
both British and American psychiatrists. The American psychiatrists not only reported almost twice as many symptoms per patient as did the British psychiatrists, but in addition they reported differences in the types of symptoms observed. Specifically, the Americans were much more likely to "observe" signs and/or feelings of inadequacy, dependency, and social underachievement. ${ }^{110}$ Another study coinparing the judgments of British and American psychiatrists confirmed that, as between the two groups, there is both a wide variation in diag. nostic preferences, and a strong tendency to perceive the severity of a patient's symptoms differently-though there was general agreement as to which "symptoms" the patients manifested."11 In short, "psychiatrists in both countries perceived the same groups of symptoms, but interpret [sic] them in different ways." ${ }^{112}$ Specifically, American psychiatrists and, among the British, those who were older, tended to view patients as having more severe pathology. And a third study, in which a filmed interview was shown to British and American psychiatrists, again found that British psychiatrists see different patterns of pathology and less pathology generally-especially less severe pathology. ${ }^{113}$

\section{E. Personal Bias}

The factor which may most influence diagnosis is the clinician's own personality, value systen, self-image, personal preferences, and attitudes. Raines and Rohrer, in their study of psychiatric predictions of combat officer candidate success, found that psychiatrists were predisposed to observe different personality traits in the same individual. ${ }^{114}$ Moreover, the various traits and symptoms observed were not valued equally by the different psychiatrists. The authors concluded that:

... the psychiatry decision involves not only the psychiatrist's emotional prob'ems and defenses, but also his entire value systein and probably his self-image. . . .

110. Sandifer, Hordern, Timbury \& Green, Similarities and Differences in Patient Evaluation by U.S. and U.K. Psychiatrists, 126 AM. J. Psхchut. 206 (1969) [hereinafter cited as Sandifer].

111. Copeland, et al., supra note 28. The formal definition of "schizophrenia" is no different in Britain than in the United States, but American psychiatrists are apparently willing to attach the label to a much greater range and variety of individuals than are British psychiatrists. See Kendell, Cooper, Gourlay, Copeland, Sharpe \& Garland, The Diagnostic Criteria of American and British Psychiatrists, 25 ARch. GeN. PSYChIAT. 123 (1971).

112. Copeland, et al., supra note 28, at 635.

113. Katz, Cole \& Lowery, supra note 28.

114. See Raines \& Rohrer, supra note 10. 
This results in a greater sensitivity on the part of the psychiatrist for certain facets of the patient's personality structure, and a greater perceptual distortion ... of other facets .... Once perceived, correctly or distortedly, each itein is subjected to the psychiatrist's value system. ${ }^{115}$

In a follow-up study, the same authors discovered that psychiatrists' observations and perceptions of their patients tend to reflect their own personality structures and problems. ${ }^{116}$ A related study concluded that the psychiatrist's personal values (such as his attitude toward the value of military service and doing one's "duty") often influence the supposedly neutral clinical judgment as to whether an individual is psychologically "fit for duty." "117

Grosz and Grossinan present evidence suggesting that the clinicians' varying personal biases may account for the significant differences in their evaluation of ambiguous and emotionally charged case history data. ${ }^{118}$ They summarize their findings, as follows:

.. . The more complex, ill-defined, ambiguous, unfamiliar and uninformative the data, the more strongly do the observer's set, focused attention, expectation, bias and other intra-observer conditions come into play and influence his perception, judgment, and decision . . . . The possibility exists that such judgments are less informative about the patient whom they are meant to describe than about the clinician who makes them. They may reveal the clinician's concepts of norms or his toleration of deviations conipared to those of his peers, his clinical orientation and attitudes toward certain aspects of the patient's history, his clinical experience and interests, and perhaps even his own background and personality. ${ }^{119}$

Their conclusions are borne out by others. For instance, Dickes, Simons, and Weisfogel demonstrate that the unconscious conflicts of climicians often cause distortions in perception, and misapprehension of the patient's true condition. ${ }^{120}$ And in the context of sanity hearings

115. Id. at 732-33.

116. Raines \& Rohrer, The Operational Matrix of Psychiatric Practice II: Variability in Psychiatric Impression and the Projection Hypothesis, 117 AM. J. PsYchiAT. 133 (1960). See also Rosenzweig, Vandenberg, Moore, \& Duhay, A Study of the Reliability of the Mental Status Examination, 117 AM. J. Psychiar. 1102 (1961) (different interviewers elicit significantly different aspects of a patient's personality).

117. Sullivan, Influence of Personal Values on Psychiatric Judgment: A Military Example, 152 J. NeRV. MENT. Dis. 193 (1971).

118. Grosz \& Grossman, The Sources of Observer Variation and Bias in Clinical Judgments: I. The Item of Psychiatric History, 138 J. NeRv. MENT. Dis. 105, 111 (1964).

119. Id.

120. Dickes, Simons \& Weisfogel, Difficulties in Diagnosis Introduced by Unconscious Factors Present in the Interviewer, 44 PSYchIAT. QUAR. 55 (1970). 
Pugh found that the ultimate determinations are strongly influenced by the personal idiosyncracies of the examining psychiatrist. ${ }^{121}$

Strupp found that therapists' perceptions of a patient presented in a film interview varied according to the therapist's experience and his attitude toward the patient. ${ }^{122}$ As an illustration of the latter factor, if for some reason the therapist disliked the patient the result was often a poor prognastic evaluation. Braginsky and Braginsky suggest a possible context in which a psychiatrist might develop a dislike for a patient. Their study showed that mental health professionals view patients who express radical political views as more disturbed than patients who voice the same psychiatric complaints, but whose political views are more conventional. They also discovered that voicing criticism of the mental health profession, whether from a radical or conservative perspective, may substantially increase a patient's psychopathology in the eyes of mental health professionals, while flattering the profession tends to decrease a patient's otherwise perceived symptomatology. ${ }^{123}$ Numerous other studies confirm that the clinician's personal values and attitudes strongly influence diagnosis and judgment. ${ }^{124}$

We have seen that idiosyncratic values and attitudes often influence psychiatric diagnoses and prognoses. Moreover, there is evidence that values and attitudes charaoteristic of psychiatrists as a group may influence other psychiatric judgments, such as the decision whether or not to release hospitalized patients. First, psychiatrists as a group may have little tolerance for deviant behavior and consequently may require a high standard of community adjustment. ${ }^{125}$

121. Pugh, The Insanity Defense in Operation: A Practicing Psychiatrist Views Durham and Browner, 1973 WASH. U.L.Q. 87.

122. Strupp, The Psychotherapist's Contribution to the Treatment Process, 3 Berav. ScI. 34 (1958). See also Wallach \& Strupp, Psychotherapist's Clinical Judgments and Attitude Toward Patients, 24 J. Clin. \& Consult. Psychol. 316 (1960), (showing that high motivation for treatment, independent of the degree of "pathology," predisposes clinicians to like patients better and, in turn, to attribute a more favorable prognosis to them. Individuals who disagree with their psychiatrist's perception of their needs-including the need for hospitahization-will be considered more disturbed than if they agree with the psychiatrist's judgment).

123. Braginsky \& Braginsky, Psychologists: High Priests of the Middle Class, PsYchol. TODAY, Dec. 1973, at 15, 139. Thus, patients who voice dissatisfaction with hospitalization and the treatment they are receiving are likely to be perceived as sicker than originally thought, and more in need of hospitalization-a classic Catch-22 situatiou. See also note 122 , supra.

124. See, e.g., Mehlman, The Reliability of Psychiatric Diagnosis, 47 J. Annorm. \& Soc. PSYCHOL. 577 (1952); Pasamanick, et al., supra note 30.

125. There is evidence that psychiatrists have a lower "tolerance" for abnormal behavior than other professionals (lawyers, in particular). Brown, Lawyers and Psychiatrists in the Court: Afterword, 32 MD. L. REv. 36, 39 (1972). It is likely that many psychiatrists would characterize certain behavior as dangerous which laymen, including judges and juries, would not. 
Second, psychiatrists as a group are likely to be paternalistic and therefore relatively insensitive to considerations of civil liberty. ${ }^{126}$ Third, psychiatrists may be susceptible to family pressures to commit. ${ }^{127}$ Fourth, psychiatrists may have a vested interest-for example, in the patient's continued participation in an experimental treatment program -which can only be fulfilled by the patient's continued confinement. ${ }^{128}$ Finally, psychiatrists may view poor adjustment to the hospital as a negative indicator of potential community adjustment, rather than as dissatisfaction with incarceration. ${ }^{129}$

\section{F. The Inadequacies of the Diagnostic System and the Ambiguity of Psychiatric Data}

In the follow-up study to Beck, ${ }^{130}$ Ward and his collaborators asked pairs of psychiatrists who had interviewed the same patients to discuss their conclusions in an attempt to discover why their diagnoses had differed. Two major sources of error were discerned. One source of error was inconsistency of perception among diagnosticians and assignment of different weights to the same symptoms. The largest sources of error derived from the inadequacies of the diagnostic system-the excessively fine distinctions required, the uncertain criteria for particular diagnoses, and the requirement of choosing a predominant diagnostic category when none was clearly evident. ${ }^{131}$

126. A recent attitudinal survey of California psychiatrists suggests that since most of them are confident that their clinical judgments provide an adequate basis for civil commitment, they are inpatient with legal, civil libertarian limitations on the implementation of such judgments. See ENKI ReSEARCH INSTITUTE, A STudy OF CALIFORNIA's New MeNTAL Health LAw 210-11, (ENKI Corp., California 1972).

127. Familial and adıninistrative pressures often and significantly may influence both psychiatric decisions regarding the need for hospitalization and the supposedly independent evaluation of emotional impairment. For empirical evidence of this see Greenley, Alternative Views of the Psychiatrist's Role, 20 Social Problems 252 (1972). His data also suggest that psychiatrists often claim to base their ultimate decision solely on the patient's condition when, in fact, it is the product of outside pressures as well. See also Wilde, Decision Making in a Psychiatric Screening Agency, 9 J. Health \& Soc. Benavior 215 (1968). But cf. Gove, Who is Hospitalized: A Critical Review of Some Sociological Studies of Mental Illness, 11 J. HEaLTH \& Soc. BeHAVIOR 294 (1970).

128. See, e.g., Law's Labor Lost, 40 Psxchiat. Quar. 150, 156 (1966) (Editorial comment).

129. See note 123 supra, and accompanying text.

130. Beck, et al., supra note 24 .

131. Ward, et al., supra note 106. A third source of error, which was relatively unimportant in the Beck study where the interviews were held only minutes apart, was the inconsistency of patient behavior between different interviews. Under more typical conditions, other sources of unreliability would also play a role: inexperienced or incompetent diagnosticians, language and cnltural differences between clinicians and patients, the effect of different clinical settings, differences in diagnostic preferences, differences in the time available for evaluation, psychiatric biases, and so forth. Cf. Smith, A Model for Psychiatric Diagnosis, 14 ARCH. Gen. PsychIat. 521 (1966). 
But avoiding this problem by assigning patients to broad categories in lieu of making more specific diagnoses serves only to create an artificial aura of reliability and validity. As lias previously been pointed out, of the various diagnostic labels used by psychiatrists, the label "psychosis" is probably the most reliable, with agreement to be expected 60-70 percent of the time. ${ }^{132}$ Moreover, that diagnosis may even possess a certain limited validity in that it may accurately indicatc that the patient manifested (at least in the psychiatrist's view) one of the five classical syinptoms of psychosis: hallucinations, delusions, lack of reality testing, disordered thought processes, or severely withdrawn behavior. ${ }^{133}$ However, there is no evidence that a diagnosis of psychosis-or, for that matter, any other diagnosis-validly indicates that the patient exhibited (or even was perceived to exhibit) more than one of the symptoms associated with that diagnosis.

For example, in a recent study eight confederates, all normal and healthy, gained admission to 12 psychiatric hospitals by complaining that they were hearing voices saying "einpty," "lollow," and "thud."134 Otherwise, no significant falsification of "person, history, or circun1stances" was made. Upon admission to the psychiatric wards, the pseudo-patients immediately ceased claiming to hear voices and sinulated no other abnormal symptoms. With the exception of nervousness brought on by the circumstances of their commitment, their subsequent behavior was perfectly normal. All but one of the patients had been admitted with a diagnosis of schizophrenia, and all were discharged with a diagnosis of "schizophrenia in remission." The diagnosis was a valid indication that the pseudo-patients exhibited one of the characteristic symptoms of schizophrenia-hallucinations. However, it was not a valid indication that the pseudo-patients exhibited any of the other symptoms characteristic of schizophrenia, officially described as follows:

. . . characteristic disturbances of thinking, mood and behavior .... alterations of concept formation which may lead to misinterpretation of reality and sometimes to delusions and hallucinations, which frequently appear psychologically self-protective. Corollary mood changes imclude ambivalent, constricted and inappropriate emotional responsiveness and loss of empathy with others. Behavior may be withdrawn, regressive, and bizarre $\ldots .$. . 135

132. See text accompanying notes 19-28.

133. We have not seen any evidence that persons diagnosed as "psychotic" actually manifest one of the five classical symptoms of psychosis. There is some evidence, however, that a diagnosis of psychosis is a valid indication that the examiner perceived one of the five classic symptoins. See Nathan, et al., supra note 47. But of. Struass, infra at note 136, and the text accompanying notes 136-40.

134. Rosenhan, supra note 96, at 253.

135. DSM-II, supra note 13 , at 33. 
The psuedo-patients exhibited no symptom other than a single, innocuous hallucination, and even that one symptom was no longer manifested after admission.

Ward's findings of inconsistent psychiatric perception are echoed in an interesting study by Strauss which shows that (1) it may often be very difficult-if not impossible-to determine whether a given individual is, or is not, experiencing hallucinations or delusions (the key diagnostic criteria of the psychoses, especially of schizophrenia) and (2) even if the person is, such phenomena should be viewed in terms of a continuum of reality distortion, rather than simply as being present or absent. ${ }^{136}$ Of 119 acutely disturbed patients comprising Strauss' study, 74 reported experiences that were considered by the examiner to be possibly but not clearly delusional, and 41 reported experiences that were considered to be possibly but not clearly hallucinatory. Psychiatrists predisposed to observe symptoms of disorder could have interpreted these ambiguous experiences as delusions or hallucinations, which would have justified a diagnosis of psychosis or perhaps schizophrenia. But, as Strauss points out in summarizing his findings:

[Acute psychiatric] patients describe ... such a variety of perceptual and ideational experiences that in many cases a simple "presence" or "absence" rating would make experiences seem much more distinct than they actually were. Since it was so difficult to dichotonize ideational and perceptual aberrations into categories of hallucinations and delusions on the one hand and "normal" on the other, the concept of schizophrenia as a discrete disorder for which these symptoms are often considered diagnostic is also brought into question..$^{137}$

136. Strauss, Hallucinations and Delusions as Points on Continua Function, 21 ARCH. GEN. Psychiat. 581 (1969) [hereinafter cited as Strauss].

137. Id. at 586. See also Freedinan, Various Etiologies of the Schizophrenic Syndrome, 19 Dis. NERv. SxST. 1 (1958); Opler, Schizophrenia and Culture, 197 Scr. AMER. 103 (1957); Strauss, Diagnostic Models and the Nature of Psychiatric Disorder, 29 ARCH. GEN. Psychiat. 445 (1973).

Based on his data, Strauss suggests three reasons why reported experiences may often be difficult to classify as delusional or nondelusional, hallucinatory or nonhallucinatory (that is, psychotic or nonpsychotic). First, it is often difficult to discern just how much a patient (who, for example, feels guilty for causing someone's death, or feels that he or she is a burden to others) is, or is not, distorting reality. Second, an evaluation of the patient's psychopathology may be colored by an awareness-or lack thereof-of certain factors in a patient's history or environinent. For example, the psychiatric and diagnostic implications of a belief that "the devil is trying to influence me" may be difficult to evaluate if the patient has had fundamentalist religious training, and it may likewise be difficult to evaluate, or to characterize as psychotic or nonpsychotic "experiences such as that of a woman who heard the neighbors talking about her through the walls of her cheaply built apartment." Strauss, supra note 136, at 583. Third, it may not be clear just how rigidly or strongly the patient adheres to his or her belief in the distorted ideas or perceptions lie or she may be experiencing, 
Not only may the experiences described be ambiguous, but a significant ambiguity is raised by the diagnostic manual of the American Psychiatric Association-which presumably provides the basis for psychiatric diagnoses. In one part of the manual psychiatrists are instructed to diagnose as psychotic only persons whose "mental functioning is sufficiently impaired to interfere grossly with their capacity to meet the ordinary demands of life."138 That instruction, standing alone, would suggest to laymen and to psychiatrists that almost everyone diagnosed as psychotic would meet the criteria for involuntary commitment-mentally ill and in need of care and treatment-in use in most states. In the next paragraph of the inanual, however, psychiatrists are instructed that they may diagnose individuals as falling within the sub-categories of psychosis such as shizophremic, paranoid, manic-depressive, even if the individuals "are not in fact psychotic."130 Consequently, an assumption that an individual diagnosed as schizophrenic requires involuntary care and treatment often may be erroneous. Psychiatrists would be the first to acknowledge that millions of persons who could be diagnosed as schizophrenic do not require hospitalization. Unless one realizes that a person may fall within a subcategory of psychosis without being "in fact" psychotic, the use of diagnoses such as schizophrenia is misleading and can prejudice the prospective patient's rights. ${ }^{140}$

\section{G. Additional Reasons Why Psychiatric Predictions of Dangerousness Are Invalid}

While all the foregoing factors may also dispose psychiatrists to assess erroneously a patient's capacity for violence, there are addi-

however fleetingly. Strauss concludes as follows:

It might be both more accurate and more useful to conceptualize hallucinations and delusions as points on continua of function and to conceptualize schizophrenia similarly as representing a point or points on continua of function. The suggested paraineters of these continua of function are: the degree of a patient's conviction of the objective reality of a bizarre experience, the degree of direct cultural or stimulus determinants of an experience; the amount of time spent preoccupied with the experience; and the degree of implausibility of an experience.

Strauss, supra note 136, at 586.

138. DSM-II, supra note 13, at 23.

139. Id.

140. To complicate the issue further, psychiatrists often diagnose individuals as psychotic whether or not they are able to care for themselves in the community. In practice, a person may appear to exhibit one of the five classical symptoms of psychosis-hallucinations, delusions, lack of reality testing, disordered thought processes, or severely withdrawn behavior-and therefore will be diagnosed as psychotic, even though the symptoms are not so extensive or debilitating as to require involuntary care and treatment. See Nathan, et al., supra note 47, at 711-14. See also note 166 infra, and accompanying text. 
tional, more particularized, reasons why psychiatric predictions of "dangerousness" are of such limited validity.

Unlike the task of formulating a diagnosis, psychiatrists are not even trained in the assessment or prediction of "dangerousness." Medical schools do not offer courses in the prediction of dangerous behavior; nor are there textbooks explaining the method and criteria by which such assessments are to be made. Rappeport, for instance, conducted a thorough research of the literature and found "no articles that could assist [psychiatrists] to any great extent in determining who might be dangerous, particularly before he commits an offense."1*1 Moreover, no traits, symptoms, or conditions which are useful predictors of dangerous behavior have been identified. Rubin, looking for such "characteristics of danger," found that the literature was "sparse, disorganized, and impressionistic."142

Guttmacher studied 20 individuals who had been hospitalized for psychiatric reasons prior to committing a homicide. ${ }^{143}$ After searching the hospital records and case histories for clues or common features which might have alerted the hospital staff to the patients' dangerousness, his conclusion was that it was not possible "to decipher in these cases any symptoms which they presented in common that might act as warning signs of impending catastrophe."144

In summary, training and experience do not enable psychiatrists adequately to predict dangerous behavior. Rather, such predictions are determined by the time and place of diagnosis, the psychiatrist's personal bias, social pressures, the class and cultures of the respective parties, and other extraneous factors. Finally, even if psychiatrists could accurately determine which persons are inentally ill, that determination would not assist them in predicting dangerousness because, as has been previously noted, there is no correlation between mental illness and dangerous behavior. To the contrary, the mentally ill may even be less dangerous than the population as a whole. ${ }^{145}$ Moreover,

141. Rappeport, Lassen \& Hay, A Review of the Literature on the Dangerousness of the Mentally Ill, in The Clinical Evaluation of the Dangerousness of the MENTALLY ILL, 72, 79 (J. Rappeport ed. 1967).

142. Rubin, supra note 55, at 399.

143. Guttmacher, A Review Of Cases Seen by a Court Psychiatrist, in The Cuinical Evaluation of the Dangerousness of the Mentally Ill, 17 (J. Rappeport ed. 1967).

144. Id. at 27.

145. See notes 73 and 74 supra. Additional empirical studies supporting this proposition are described in Ennis, Civil Liberties and Mental Illness, 7 CRm. LAT Bull. 101 (1971). See also Nat'l Inst. of Mentar Hearth SchizophrentaIs There AN ANswer? (DHEW Pub. No. (HSM) 73-9086, 1972); Greenland, Evaluation of Violence and Dangerous Behavior Associated with Mental Illness, 3 SEM. IN Psychiat. 345 (1971); Schmideberg, supra note 86 . There is no evidence that, after having been released from a hospital, people diagnosed as schizophrenic are more 
dangerous behavior does not occur in a vacuum. As Guttmacher has noted, "one cannot anticipate with accuracy [the] social situations which the released . . . patient will have to meet."146 In all probability, then, whether a person will commit a dangerous act depends in large part upon fortuitous and unpredictable events. ${ }^{147}$

\section{III}

\section{LEGAL CONSEQUENCES AND RECOMMENDATIONS}

From the preceding studies it is possible to draw the following conclusions. Psychiatric diagnoses are quite unreliable. ${ }^{148}$ Psychiatrists are more likely to disagree than to agree about specific diagnoses such as psychotic depression, paranoid schizophremia, or passive-agressive personality; and while diagnoses limited to the broad categories of functional disorder are more reliable, in actual practice psychiatrists are almost as likely to disagree about such diagnoses as they are to agree. ${ }^{149}$ Although the validity of psychiatric diagnoses has not yet been carefully studied, the relevant evidence suggests that it is quite limited. At the least, it is clear that psychiatric diagnoses-especially the diagnostic categories of psychosis and schizophrenia-often suggest the presence of symptoms and/or degrees of psychopathology that simply do not exist. It is equally clear that psychiatrists have absolutely no expertise in predicting dangerous behavior-indeed, they nlay be

prone to violence than the average person, NAT'L INST. OF MENTAL HeALTH, supra. Of course, some mentally ill persons do say or think dangerous things, but they rarely follow through. One study, for example, found the correlation between fantasized aggression, as measured by the Thematic Apperception Test (a major psychological test), and behavioral aggression to be quite low. Shapola, The Effectiventess of TAT as a Measure of Aggression: A Review, 46 Indian J. OF PsYChol. 319 (1971).

146. Guttmacher, supra note 143 , at 27.

147. Monahan has suggested that research, resources, and energy should be shifted from the so-far futile attempt to identify violence-prone persons to the identification and modification of situations conducive to violence.

... Such a chauge in tack might lead to appreciable gains in preventive efficiency (it could hardly do worse than current efforts at person identification), and would obviate the seemingly insurmountable problein of uujustly intervening in the lives of innumerable false positives.

Ultimately, it may be possible to classify both persons and environments in a typology of violence. One might then predict with some validity that a person of a given type will commit a violent act if he remains in one type of environment, yet will remain non-violent if placed in another situational context.

Monahan, supra note 72 , at 18 (paging of prepublication draft).

148. An exception to this statement is the diagnosis of organic psychosis, which is apparently reliable about $80-90$ percent of the time. Otherwise, psychiatrists themselves recognize that diagnostic judgments-even broad diagnostic judgments-are so unreliable as to interfere seriously with meaningful research aud treatment.

149. Psychiatric judgments, though unreliable, may not be substantially more unreliable than some types of medical judgments. Falek and Moser examined eight studies of "reliability in the diagnosis of physical disorders." Falek \& Moser, supra 
less accurate predictors than laymen - and that they usually err by overpredicting violence.

Finally, whether a prospective patient will be labelled psychotic or nonpsychotic, schizophrenic or nonschizophrenic, dangerous or nondangerous, able or unable to care for himself or herself may be determined by one or more of the following factors: the theoretical orientation and methodology of the examining psychiatrist; the socio-economic and cultural background of the patient and psychiatrist; and the time, place, and circumstances of the psychiatric examination. In summary, there is good reason to believe that psychiatric judgments are not particularly reliable or valid, and that psychiatric diagnoses and predictions convey more erroneous than accurate information. The legal implications of this demonstrated psychiatric fallibility are obviously far-reaching.

\section{A. Psychiatrists Should Not Be Permitted To Testify as Experts in Civil Commitment Proceedings}

\section{Psychiatric Judgments are not Sufficiently Reliable or Valid to Justify Their Admissibility under Traditional Rules of Evidence}

An exception to the ordinary rules of evidence has been created to permit experts to testify in court as to their opinions, conclusions, and judginents. With the exception of psychiatrists, witnesses are required to prove their expertise before courts will permit thein to testify as experts. If that same proof were required of psychiatrists, they could not qualify as expert witnesses. Support for this proposition

note 24. See particularly id., Table 4, "Diagnostic Concurrence In Physical Disorders". They found that "diagnostic concurrence for many physical disorders is oftentimes as inaccurate as that observed in studies of schizophrenia." Id. at 11 . For example, three cardiologists could agree on the presence or absence of angina in only 45 percent of 57 chest pain patients. Id. Another study of electrocardiogram evaluations by 55 observers revealed "inter-observer variation ranging from 21 percent to 70 percent." Id. In a third study, directed more at validity than at reliability, almost half of 1,197 electrocardiograms identified as abnormal by a computer process "were considered normal by standard questionnaire and physician evaluation." Id. Another study found that 3 to 13 percent of pap smear tests identifying cervical cancer were false negatives. Id. We have concentrated in this Article on the unreliability and invalidity of psychiatric judgments not because psychiatric judgments are more unreliable and mvalid than certain medical judgments, but because psychiatric judgments, unlike medical judgments, serve as the justification for involuntary treatments and interventions.

We hope this Article will prompt similar investigations of the reliability and validity of judgments made by other professionals. We suspect that psychiatrists will fare reasonably well when their judgments are compared with the judgments of school guidance counselors, parole boards, employment counselors, social workers, and so forth. 
may be provided by analogy to the judicial treatment of polygraph results.

There is no question that psychiatric judgments are far less reliable and valid than polygraph judgments. ${ }^{150}$ Although the evidence is still accumulating, a conservative estimate is that an experienced polygraph examiner can correctly detect truth or deception about 80 to 90 percent of the time. ${ }^{151}$

Significantly, one study has indicated "that an examiner is more mclined to report a guilty subject innocent than he is to report an innocent subject guilty." ${ }^{152}$ The converse is true of psychiatrists; if doubt exists, it almost always is resolved to the patient's disadvantage; predictions of dangerousness afford the prime example.

Despite this proven reliability and validity of polygraph tests, only a liandful of state and federal trial courts have received polygraph reports in evidence, and then usually for only limited purposes. ${ }^{153}$ More-

150. See generally, ZISKIN, supra note 5, at 5-6; Collier, Again, the Truth Ma4 chines, N.Y. Times, Nov. 25, 1973, (Magazine) at 35 [liereinafter cited as Collier]; Inbau \& Reid, The Lie-Detector Teclnique: A Reliable and Valuablc Investigative Aid, 50 A.B.A.J. 470 (1964); Shattuck, Brown \& Carlson, The Lie Detector as a Surveillance Device, ACLU REPORTS (Feb. 1973); Note, Problems Remaining For the 'Generally Accepted' Polygraph, 53 Boston U.L. REv. 375 (1973); Note, Hypnosis, Truth Drugs, and the Polygraph: An Analysis of their Use and Acceptance by the Courts, 21 U. FLA. L. REv. 541 (1969); and Annot., Physiological or Psychological Truth and Deception Tests, 23 A.L.R.2d 1306 (1952).

151. One study by polygraph enthusiasts claims that 94 percent of all subjects can be tested accurately, with less than 1 percent error. E.g., J. REID \& INBAU, TRuTH and Deception: The Polygraph ("Lie Detector") Technique 234 (1966). Another study claims to have achieved definite results 95.6 percent of the time with only three known errors out of 4,093 reports. F. InbaU, LiE Detection and Criminal INTERROGATION (1968). Two experimental studies using students reported that a polygraph examiner could correctly identify 100 percent of all "innocent" students, and 88 to 94 percent of all "guilty" students. Davidson, Validity of the Guilty Knowledge Technique: The Effects of Motivation, 52 J. APPL. PsYcHol. 62 (1968); Lykken, The GSR in the Detection of Guilt, 43 J. APPL. PsYchol. 385 (1959). One of the more carefully controlled studies concluded that polygraph operators accurately can determine truth or deception in 87.75 percent of all cases. Hovarth \& Reid, The Reliability of Polygraph Examiner Diagnosis of Truth and Deception, 62 J. CRrM. LAW CRIMTN. \& P. S. 276 (1971) [hereinafter cited as Hovarth \& Reid]. In that study ten polygraph operators (seven experienced and tlree inexperienced) were shown the polygraph records of 40 examinations having never seen the subjects. "Subsequent to the polygraph examination each of the selected cases had been solved by a fully corroborated confession of the guilty subject." Id. at 277 . Other corroborated cases were not used because the polygraph records in those cases "were dramatically indicative of truth or deception." Id. Twenty of the records were from verified guilty subjects and twenty from verified innocent subjects.

The ten examiners achieved an average 87.75 percent accuracy in solving the cases, i.e., in correctly detecting the guilty subjects and correctly identifying the innocent subjects .... The experienced examiners were successful in 91.4 percent of their diagnoses; the inexperienced in only 79.1 percent.

152. Hovarth \& Reid, supra note 151, at 279.

153. Those cases are discussed in Comment, Pinocchio's New Nose, 48 N.Y.U.I. 
over, no appellate court has approved the admission of polygraph reports over the objection of a party. ${ }^{154}$

In State v. Valdez, ${ }^{155}$ for example, the Supreme Court of Arizona refused, absent stipulation, to permit the use of polygraph evidence in court, even though it believed that under conservative estimates polygraph operators could correctly determine truth or deception in 75 to 80 percent of all cases (15 to 20 percent inconclusive and less than 5 percent proven error). ${ }^{150}$ The court gave five reasons for excluding he detector results: a) the possibility that extraneous qualities or characteristics of the subject might yield erroneous results; b) the tendency of judges and juries to treat he detector evidence as conclusive; c) the lack of standardized testing procedures; d) the difficulty of evaluating examiner opinions; and e) the nonacceptance of the technique by appropriate scientific bodies.

Each of these objections providcs a cogent reason also to exclude psychiatric judgments: a) extraneous qualities of psychiatric patients - such as their socio-economic class-may substantially influence psychiatric judgments; b) judges and juries usually defer to psychiatric judgments, ${ }^{157}$ c) psychiatric interview procedures are unstandardized; d) it is difficult for judges and juries to evaluate the validity of individual psychiatric judgments; and e) psychiatrists and behavioral scientists who have studied the reliability and validity of psychiatric judgments almost unanimously agree that such judgments are of low reliability and validity. ${ }^{158}$

Whatever may be said for the reliability and vahdity of psychiatric judgments in general, there is literally no evidence that psychiatrists reliably and accurately can predict dangerous behavior. To the contrary, such predictions are wrong more often than they are right. ${ }^{159}$ It is inconceivable that a judgment could be considered an "expert" judgment when it is less accurate than the flip of a coim.

Accordingly, psychiatrists should not be permitted to testify as ex-

Rev. 339 (1973) [hereinafter cited as Pinocchio]; Note, The Emergence of the Polygraph at Trial, 73 Colum. L. Rev. 1120 (1973).

154. See the cases and authorities cited in Pinocchio, supra note 153, at 341 n.16.

155. 91 Ariz. 274, 371 P.2d 894 (1962).

156. Id. at $282,371 \mathrm{P} .2 \mathrm{~d}$ at 900.

157. See authorities cited in note 1 supra.

158. One student commentator has used the reliability of polygraph judgments vis-a-vis psychiatric judgments as a reason for urging the admissibility of polygraph judgments. Note, The Polygraph Revisited: An Argument for Admissibility, 4 SuFF. U.L. REv. 111, 117 (1969). Similarly, polygraph operators often compare the reliability of their judgments with the reliability of psychiatric judgments as a basis for admitting polygraph judgments in evidence. See, e.g., Collier, supra note 150, at 110. Although the comparisons are valid, we suggest that neither type of judgmeut is sufficiently accurate to justify admissibility.

159. See, e.g., the two Baxstrom studies, supra, notes 59 and 60. 
pert witnesses ${ }^{160}$ until they can prove through empirical studies that their judgments are reliable and valid. ${ }^{161}$

\section{Psychiatric Judgments do not Convey Meaningful or Otherwise Unavailable Information about the Issues Relevant in a Civil Commitment Proceeding}

It is our contention that psychiatric diagnoses often convey more inaccurate than accurate information about an individual, in that a diagnosis suggests that the individual manifests the range of symptoms associated with that diagnosis when, in fact, the individual may

160. Psychologists have often not been permitted to testify as experts absent "a showing of at least a semblance of scientific acceptance of the psychologist's ability to formulate a dependable conclusion under all of the circumstances of the case." People v. Spigno, 156 Cal. App. 2d 279, 288, 319 P.2d 458, 463 (1957). At least it is required that "he can substantiate [his findings] by evidence that would be acceptable to recognized specialists in the saine field." State v. Padilla, 66 N.M. 289, 298, 347 P.2d 312, 318 (1959). See also Jenkins v. United States, 307 F.2d 637 (D.C. Cir. 1962).

These standards are hardly rigorous but they are more rigorous than the standards apphed to psychiatrists, who need only show that they are psychiatrists. Yet psychologists may well be more accurate in their judgments than psychiatrists. At the least their test results are subject to direct inspection by other experts. See generally Lassen, The Psychologist as an Expert Witness in Assessing Mental Disease or Defect, 50 A.B.A.J. 239 (1964); Levine, The Psychologist as Expert Witness in "Psychiatric" Questions, 20 Clev. ST. L. REv. 379 (1971); Comment, The Psychologist as an Expert Witness, 15 KANS. L. REv. 88 (1966).

We do not suggest that judginents made by psychologists are sufficiently reliable and valid to qualify psychologists as "experts" in civil commitınent cases. They probably are not. See Ziskin, supra note 5 . We do suggest, however, that if psychiatrists were required to make the same minimal showing of expertise that often is required of psychologists before offering certain conclusions-for instance, that a prospective patient is dangerous-such conclusions would not be admissible. There is, for example, not even a semblance of scientific evidence to substantiate any psychiatrist's claim that he or she accurately can predict violent behavior, especially in the absence of a recent overt act of violence.

161. Objective, rather than subjective, validation is the central premise of the scientific method. One example of the law's insistence on objective rather than subjective validation is the recent flood of court decisions requiring employers to prove, through objective studies, that the tests used to discriminate among job applicants actually measure the applicants' qualifications for the job. E.g., Griggs v. Duke Power Co., 401 U.S. 424 (1971); Chance v. Bd. of Exammers, 458 F.2d 1167 (2d Cir. 1972); Vulcan Society v. Civil Service Comm., 360 F. Supp. 1265 S.D.N.Y. 1973). Those decisions, in turn, rely upon the Equal Employment Opportunity Commission's Guidehines on Employee Selection Procedures, 29 C.F.R. $\$ 1607$ et seq., which require "empirical evidence," based on "studies," that a test is valid. Id, at $\$ 1607.5$ (a). See generally, Bernhardt, Griggs v. Duke Power Co.: The Implications for Private and Public Employers, 50 Tex. L. Rev. 901 (1972); Cooper \& Sobol, Seniority and Testing Under Fair Employment Law: A General Approach to Objective Criteria of Hiring and Promotion, 82 HARv. L. REv. 1598 (1968); Wilson, A Second Look at Griggs v. Duke Power Company: Ruminating on Job Testing, Discrimination, and the Role of the Federal Courts, 58 VA. L. REv. 844 (1972). 
exhibit only one, or even none, of those symptoms. ${ }^{162}$ On the one hand, the label "psychosis," for example, tells us that the patient presumably exhibits one of five symptoms, which could just as -easily be described directly without using the diagnostic label. On the other hand, it tells us nothing about the individual's potential dangerousness, the expected duration of his or her condition, whether it can be treated, and, if so, how. Moreover, it does not purport to tell us whether the individual is friendly or unfriendly, cooperative or uncooperative, happy or depressed. In short, the diagnosis itself answers none of the questions that conceivably could be important to a judge or jury in a civil commitment proceeding. ${ }^{163}$ Indeed, though a diag-

162. See notes $138-40$, supra, and accompanying text.

163. See, e.g., Washington v. United States, 390 F.2d 444, 454 (D.C. Cir. 1967): ... it does not help a jury of laymen to be told of a diagnosis limited to the esoteric and swiftly changing vocabulary of psychiatry. Every technical description ought to be "translated" in terms of "what I mean by this," followed by a down-to-earth concrete explanation in terms which convey meaning to laymen. A psychiatrist who gives a jury a diagnosis, for example, of "psychoneurotic reaction, obsessive compulsive type" and fails to explain fully what this means, would contribute more to society if he were permitted to stay at his hospital post taking care of patients.

We suggest that no diagnosis should be admissible. If the psychiatrist is required to detail the evidence supporting the diagnosis, no legitimate purpose is served by admitting the diagnosis. The policy reasons which led that court to restrict psychiatric testimony in the context of an insanity defense are even more compelling in the context of a civil commitment proceeding. In the insanity trial, there will always be psychiatrists testifying on both sides of the issue, thus making it clear to the jury that psychiatry is not an exact science. In the typical civil commitment proceeding, however, one or more psychiatrists will testify in favor of commitment, and no psychiatrists will testify in opposition. The insanity trial is usually sufficiently long to enable a conscientious lawyer to cross-examine an opposing psychiatrist at length on the reliability and validity of his judgments. That can be an educational process for a jury. The civil commitment hearing, on the other hand, usually lasts only a few minutes providing no realistic opportunity for the patient's lawyer to probe the biases and fallibility of the opposing psychiatrist. The insanity defense is alnost always tried before a jury. Civil commitment hearings are almost always before a judge. And there is some reason to believe that juries are more distrustful of psychiatric testimony than are judges. Psychiatric testimony in a civil commitment proceeding is likely to be more speculative and less accurate than psychiatric testimony in an insanity defense trial because in the latter the psychiatrist is simply asked to tell us whether in the past a specific dangerous act, committed in known circumstances, was or was not the product of mental disease or defect. In a civil commitment proceeding the psychiatrist is called upon to predict whether in the future, in unknown circumstances, the patient will or will not commit some unspecified dangerous act, and to predict, in addition, whether that act will be the product of self-defense, mental disease or defect, justified anger, accident, a simple criminal act caused by economic need, a desire for revenge, and so on. Moreover, it is difficult to understand why a psychiatrist is not permitted to testify as a defense witness in a criminal trial that the defendant did not have certain propensities, but is permitted to testify im a civil commitment proceeding that the prospective patient does have those propensities. See State v. Sinott, 24 N.J. 408, 132 A.2d 298 (1957); 43 N.J. Super. 1, 127 A.2d 424, 429 (1956) (opinion of the court below in the same case). See also United States v. Brawner, 471 F.2d 969, 1006 (D.C. Cir. 1972); State v. Bromley, 72 Wash. 2d 150, 
nosis of psychosis by definition indicates that an imdividual's "mental functioning is sufficiently impaired to interfere grossly with [his or her] capacity to meet the ordinary demands of life," 104 that definition is essentially meaningless because "[a]11 of us [psycliatrists] know basically psychotic individuals who continue . . . to ineet the ordinary demands of life and nonpsychotio individuals who fail utterly to measure up to this criterion." 105

By way of partial illustration, one study found that only 18.5 percent of the people living in mid-Manhattan could be considered inentally liealthy (free of significant symptoms of mental pathology) while almost 25 percent of the population was impaired and exhibited "mental morbidity." Individuals in the latter group were all characterized by "symptom formations that [had] halting, laming, or crippling effects on the performance of one's daily life." Most of those individuals probably could be considered "mentally ill" within the meaning of prevalent civil commitment provisions; ${ }^{106}$ nevertheless, they were living

432 P.2d 568, (1967). But cf. People v. Jones, 42 Cal. 2d 219, 266 P.2d 38 (1954). See also Weihofen, Detruding, supra note 1 (the author concludes that: "The main reason for the abandonment [in Brawner] of the rule in Durham v. United States [214 F.2d 862 (D.C. Cir. 1954)] was to escape the undue dominance by the experts in determining a defendant's mental responsibility."). Washington and Brawner, in short, recognize the importance of requiring psychiatric witnesses to state the bases of their conclusions if the rightful role of the trier of fact is to be preserved.

There is a substantial body of psychiatric opinion fully in agreement with the view expressed here that psychiatric diagnoses are cssentially meaningless, yet potentially prejudicial to the rights of prospective patients. See, c.g., Baur, Legal Responsibility and Mental Illness, 57 Nw. U.L. REv. 12 (1962); Diamond \& Louisell, The Psyclitatrist as an Expert Witness: Some Ruminations and Speculations, 63 Mrcн. L. Rev. 1335 (1965); Halleck, A Critique of Current Psychiatric Roles in the Legal Process, 1966 Wrs. L. REv. 379 (1966); Sadoff, Psychiatry Pleads Guilty, 51 A.B.A.J. 48 (1965).

164. DSM-II, supra note 13.

165. Jackson, supra note 13, at 69.

166. A. SRole, T. LANGNer, S. Michael, M. Opler \& T. Rennie, Mental Illness IN tHe Metropolis-The Midtown ManhatTan Study 138 (1962). The term "mental illness," which appears in most commitment statutes, is not a psychiatric term and is not even used in DSM-II. Most psychiatrists would not suggcst that a person who could be diagnosed as "mentally disordered" under DSM-II should be considered "mentally ill" within the meaning of the commitment statutes. However, the vagueness of the term "mental illness" would permit a psychiatrist to term anyone diagnosible under DSM-II as "mentally ill." And, even within the confines of DSM-II, a psychiatrist could say that if an individual is diagnosible under DSM$\mathrm{II}$, his mental functioning is "disturbed." DSM-II, supra note 13, at 39. According to Srole's data over 80 percent of the population of mid-Manhattan probably could be described as "inentally disturbed" within the meaning of DSM-II. Persons who are impotent or who have tension headaches may be diagnosed as mentally disordered under DSM-II if "emotional factors play a causative role," as could persons whose behavior is characterized by "pouting, procrastination, intentional inefficiency, or stubbornness," or by "excessive concern with conformity and adherence to standards of conscience." DSM-II, supra note 13, at 43-44, 47. Accordingly, even though most people in the United States could be described as mentally disturbed within the 
and functioning in the community. Another study, conducted by the National Institute of Mental Health, concluded that "as many as eight million people a year may suffer depression severe enough to merit being treated by a doctor, [but only] 250,000 Americans were hospitalized for the ailment last year." 167 In other words, only three percent of all persons thought to be severely depressed required hospitalization for that condition. The rest, though depressed, were able to "get along" in the community. Accordingly, since rnany "psychotic" or "severely depressed"168 persons do not require hospitalization, those labels do not assist the trier of fact in a civil commitment proceeding in deciding whether or not to commit the prospective patient.

For years "homosexuality" was listed in DSM-II as a sub-category of personality disorders. ${ }^{168}$ Recently, however, the American Psychiatric Association decided by vote that hoinosexuality should no longer be considered a inental illness. ${ }^{170}$ If all that is needed to remove large numbers of individuals from the ranks of the mentally ill and grant them the status enjoyed by the rest of society is a vote by the American Psychiatric Association, then surely other diagnostic labels are also highly suspect.

It should be obvious, then, that psychiatric diagnoses do not convey inuch ineaningful information. ${ }^{171}$ In fact, since diagnoses such as psychosis or schizophrenia have scare word qualities, they often misleadingly suggest to a judge or jury that the individual should be coinmitted to a hospital. ${ }^{172}$

meaning of DSM-II, that term, when applied to a prospective patient in a commitment hearing, is likely to convey a more sinister impression to a judge or jury.

167. Cherry \& Cherry, supra note 37 , at 38.

168. See also notes 138-40 supra, and accompanying text.

169. DSM-II, supra note 13 , at 42.

170. Alfred M. Freedman, M.D., President of the American Psychiatric Association, announced on December 15, 1973 that the APA Trustees lad voted to remove homosexuality per se from the official list of mental disorders. Over 200 psychiatrists petitioned for a referendum of the entire APA membership on this issuc. On April 8, 1974, however, the membership voted to uphold the action of the Trustees. N.Y. Times, April 9, 1974, at 12, col. 4.

171. See Frank, supra note 52, at 164.

172. For a radical critique of the entire diagnostic process, viewing the "diagnostic act" itself as a means of social control, see Miller, The Latent Social Functions of Psychiatric Diagnoses, 14 J. OfFENDER THERAPY 148 (1970). See also Kaplan, Civil Commitment "As You Like It," A Critique of the Psychiatric Approach to Crime and Correction, 23 LAW \& ConTEMP. Prob. 650 (1958); Schmideberg, Socio-legal Consequences of the Diagnostic Act, 14 J. OFFENDER THERAPY 157 (1970).

An eminent federal judge, with extensive experience in forensic psychiatry, has concluded that psychiatric judgments are not very reliable, and offer little assistance to judge or jury. Bazelon, Psychiatrists and the Adversary Process, 230 Scientific AmERICaN 18 (1974). Moreover, Judge Bazelon frequently "had occasion to find psychiatrists making decisions for motives and under pressures from outside their professional role." 1d. at 22 . 
Even more serious is the label "dangerous," which almost certainly prejudices judges and juries without conveying any meaningful information such as whether the individual is likely to cause physical injury, or mjury to property, or whether the only "danger" is that he eats too little or embarrasses himself at his job.

Recognizing that a finding of dangerousness requires a social and legal judgment that cannot be made by psychiatrists, the Supreme Court has acknowledged in a related context that:

the jury serves the critical function of introducing into the process a lay judgment, reflecting values generally held in the community, concerning the kinds of potential harm that justify the State in confining a person for compulsory treatment. ${ }^{173}$

Therefore, since psychiatric judgments, diagnostic labels, and terminology convey little meaningful information (and may convey more inaccurate than accurate information) judges and juries have no need for them in deciding the relevant issues in a civil commitment proceeding.

Juries need the testimony of ballistics experts or fingerprint experts because juries are not accustomed to making judginents in those fields. But laymen frequently make judgments about the mental condition of others. It is often necessary to make such judgenents in the business world, in will contests, and so forth. In particular, it is coinmon for laymen to make the particular judgments relevant to civil commitment proceedings. In fact, those proceedings are usually initiated not by psychiatrists but by laymen. Psychiatrists usually come into contact with prospective patients only after a layman-typically a friend, family member, or police officer-makes a judgment that the prospective patient is mentally ill or dangerous. Thus the judgments psychiatrists make, unlike the judgments made by other "experts," are not so very different from those that laymen are accustomed to make, nor are they dependent upon qualifications possessed solely by psychiatrists. Prohibiting psychiatrists from giving opinion testimony and from using psychiatric terminology when testifying would not deprive judges or juries of information they need to reach informed decisions. Indeed, we believe it would improve the accuracy and fairness of commitment decisions.

We do not suggest that psychiatrists should have no role in civil commitment hearings. We do suggest that their testimony be limited to descriptive statements which would exclude diagnoses, opinions, and predictions. We recognize that in many states lay witnesses are permitted to offer certain limited types of opinion testimony regard-

173. Humphrey v. Cady, 405 U.S. 504, 509 (1972). 
ing mental condition. ${ }^{174}$ They are permitted to do so, however, only because they lack the education or training to describe behavior in other than conclusory terms. ${ }^{175}$ Since psychiatrists supposedly are trained to observe and describe behavior in concrete terms, there is no need for them to offer opinions. ${ }^{178}$

\section{The Admission of Psychiatric Judgments in a Civil Commitment - Proceeding Denies Prospective Patients Due Process}

This point, although essential, can be simply stated. Justifying the deprivation of an individual's liberty on the basis of judgments and opinions that have not been shown to be reliable and valid should be considered a violation of both substantive and procedural due process. ${ }^{177}$ Certainly a procedure by which judges flipped coins to determine who would be committed would offend our sense of fundamental fairness. It is our contention that psychiatric judgments have not been shown to be substantially more rehable and valid.

B. If Psychiatrists Are Permitted To Testify As Experts, The Prospective Patient Should Be Afforded a Meaningful Opportunity To Cross-Examine And Call Expert Witnesses On His Behalf

\section{Cross-examination}

Since many variables other than the actual condition of an individual may influence psychiatric perceptions, descriptions, and judg-

174. E.g., United States v. Pickett, 470 F.2d 1255 (D.C. Cir. 1972); State v. Corley, 108 Ariz. 240, 495 P.2d 470 (1972); Tyler v. Tyler, 401 Ill. 435, 82 N.E.2d 346 (1948); Huddleston v. State, 295 N.E.2d 812 (Ind. Sup. Ct. 1973); Moore v. State, 293 N.E.2d 28 (Ind. Sup. Ct. 1973); State v. Randol, 212 Kan. 461, 513 P.2d 248 (1973); State v. Butner, 66 Nev. 127, 206 P.2d 253 (1949), cert. den., 338 U.S. 950 (1950); Whitmire v. State, 490 S.W.2d 179 (Tenn. Crim. App. 1972); Kelso v. Hawkins, 293 S.W.2d 807 (Tex. Civ. App., 1956); WIGMORE, EVmence §§ 1933, 1938 (3d ed. 1940); C.J.S. Evidence, $\$ 548$ (1964). Laymen, for example, may testify that an mdividual seemed "off his rocker" or "crazy" or "out of touch with reality."

175. E.g., WigmoRe, supra note 174 , at $\S 1934$. According to Wigmore, the opinion of Mr. Justice Doe, dissenting in Boardman v. Woodman, 47 N.H. 120, 144 (1866) rapidly became the generally accepted rule. Justice Doe favored opinion testimony by lay witnesses on the subject of insanity because insanity

cannot generally be so described by witnesses as to enable others to form an accurate judgment in regard to it. ... The opinion of an unprofessional witness is incompetent, not because he can give no description of the appearances which indicate sanity or imsanity, but because ordinarily he cannot give an adequate description of them.

Id. See also Norris v. State, 16 Ala. 776, 779 (1849).

176. We recognize that in some instances it is difficult to distinguish between opmions and descriptive statements-e.g., the patient is "depressed," "withdrawn," or "apathetic." But most diagnoses, and all predictions, do not suffer from this difficulty and should never be received in evidence.

177. The due process and equal protection clauses have been held applicable to civil commitment proceedings. E.g., McNeil v. Director, Patuxent Institution, 407 
ments, their validity cannot be assumed. Rather, they must be examined to determine whether the data before the psychiatrist supports his or her conclusion. We have seen that psychiatric terminology often conveys misleading information, which is usually prejudicial to the prospective patient. By way of illustration, if a recommendation that an individual be hospitalized rests upon the psychiatrist's judgment that the individual is "psychotic," cross-examination might reveal that the diagnosis of psychosis in turn rests upon the presence of only one symptom-voicing delusions, for example. Since the prospective patient did not exhibit any other symptoms of psychosis, or any violent behavior or threats, commitment could be justified, if at all, only by the presence of that one symptom-delusions. Moreover, if further crossexamination indicated that the patient's beliefs were not demonstrably true, but not particularly unreasonable or uncommon, ${ }^{178}$ exposing the psychiatrist's personal concept of "delusion" would make the limitations of his or her diagnosis apparent. ${ }^{170}$

It is our contention that psychiatric diagnoses and opinions should not be admissible in civil commitment proceedings. ${ }^{180}$ This is not to say that descriptions of the prospective patient's behavior may not be admissible. However, even though descriptive statements about behavior are assumed to be objective, too often they are based in substantial part on subjective judgment and opinions. For example, statements such as "the patient is apathetic," or "severely depressed" or "distorting reality" are not objective observations at all; the behavioral criteria for attaching such labels have been shown to vary substantially among psychiatrists. ${ }^{181}$ Although it may be that any description of an individual's emotional condition involves an'irreducible amount of subjectivity, that does not detract from the necessity of requiring psychiatrists to refine their descriptions. If a patient's behavior or threatened behavior is so disturbed as to require involuntary hospitalization,

U.S. 245 (1972); Specht v. Patterson, 386 U.S. 605 (1967); Baxstrom v. Herold, 383 U.S. 107 (1966). See also Jackson v. Indiana, 406 U.S. 715 (1972); Humphrey v. Cady, 405 U.S. 504 (1972).

178. See notes 136-37 supra, and the accompanying text.

179. See, e.g., Specht v. Patterson, 386 U.S. 605 (1967); United States v. Bohle, 445 F.2d 54, (7th Cir. 1971). In the latter, the court observed of psychiatry:

We are dealing with a field of science in which there are many variables and one in which opinions must perforce be based upon many subjective factors requiring judgmeut evaluation. Here particularly the party to be confronted by such an opinion should have the full opportunity of cross-examinaId. at 65 . tion.

180. See Section III, A, supra.

181. See Beck, et a1., supra note 24; Katz, Cole, \& Lowery, supra note 28; Copeland, et al., supra note 28; Sandifer, et al., supra note 110. Katz, Cole and Lowery termed this phenomenon a "problem of varying subjective thresholds." Supra note 28, at 945 . 
it should be possible to describe that behavior, or those threats, in concrete and unambiguous language. ${ }^{182}$

At present, most cross-examination of psychiatrists is perfunctory or nonexistent. ${ }^{183}$ One reason is that many attorneys accept psychiatric judgments at face value, possibly because they feel incapable of challenging such judgments. ${ }^{184}$ Another is that the prospective patient's lawyer, who usually is not present during the psychiatric examination on which the psychiatrist's judgment is based, has httle inforination about the individual circumstances that might have influenced that judginent. Not inconceivably, the psychiatrist might report only those portions of the prospective patient's comments and actions which would support an inference that the individual was disturbed, even though 99 percent of what he or she said and did would be entirely consistent with what we regard as normal behavior. Nor is it uncommon for psychiatrists to omit qualifying remarks, thereby making the prospective patient's statements seem more irrational than they are. ${ }^{185}$ Understandably, the patient often does not remember what the psychiatrist has omitted or misstated, or is in no position to challenge the psychiatrist's recollection of the interview. ${ }^{188}$ Consequently, ineaningful cross-examination may not be possible unless the prospective patient's lawyer was present when his or her client was examined,

182. One of the authors, B. Ennis, opposes the involuntary hospitalization of persons who could not otherwise be incarcerated under the criminal law. We both believe that if there is to be civil commitment, there is no legitimate basis for civil commitunent other than recent overt acts, attempts, or threats of overt acts. Any otlier basis for commitnent necessarily involves judgments and predictions which psychiatrists are unable to make reliably and accurately. It follows that hospital records containing diagnoses, opinions, ambiguous descriptions, predictions, or any other ambiguous, nonfactual inforInation, about which observers might well differ should not be admissible in evidence over the patient's objection, especially if the author of the entry is not available for cross-examination. See United States v. Bohle, 445 F.2d 54 (7th Cir. 1971); Lyles v. United States, 254 F.2d 725 (D.C. Cir. 1957); New York Life Ins. Co. v. Taylor, 147 F.2d 297 (D.C. Cir. 1945); State v. McGregor, 82 R.I. 437, 111 A.2d 231 (1955). But cf. People v. Kohlmeyer, 284 N.Y. 366, 31 N.E.2d 490 (Ct. of Appeals, 1940). Whether even unambignous, factual statements contained in hospital records should be admissible depends upon the purpose for which such statements are admitted. For example, records of the medication prescribed for the patient might be admissible if offerred only to show that such medication was given; they should not be admissible if offered to suggest that the patient was so disturbed as to require that medication.

183. See, e.g., Cohen, and Project, supra note 1.

184. For examples of more adequate cross-examination see ZisKIN, supra note 5, ch. 12; Kumasaka and Gupta, Lawyers and Psychiatrists in the Court: Issues on Civil Commitment, 32 MD. L. REv. 6 (1972).

185. For a specific example, see Ennis, Mental Illness, in 1969-1970 ANnuar SURVEY OF AMERICAN LAW 29, 37-40.

186. Id. Often, such interviews are conducted while the patient is agitated about being deprived of liberty, or is under the influence of various medications-circumstances which do not pronote ease of recollection. 
and therefore knows what actually happened during the psychiatric examination.

In an analogous situation the Supreme Court has ruled that a defense lawyer must be permitted to attend and observe the circumstances of a police line-up so that his subsequent cross-examination of the identifying witness will be meaningful. ${ }^{187}$ Following that exanuple, a few lower courts have suggested that prospective patients be extended the right to representation at all psychiatric examinations by a lawyer, personal physician, or friend, or, in the alternative, that a tape recording or videotape of the interview be made available to them. ${ }^{188}$ The studies collected in this article confirm the wisdom of those suggestions and the necessity for their adoption.

\section{Expert Witnesses for the Prospective Patient}

Cross-examination may suggest the fallibility of the opposing psychiatrist and the shortcomings of the psychiatric profession. But calling to the stand a psychiatrist who disagrees with the opposing psychiatrist is an even better way of forcing judges and jurors to use their common sense. ${ }^{189}$ In fact, it may be the only feasible nethod because the so-called "independent" psychiatrist, despite claims to the contrary, does not exist. ${ }^{190}$ Furthermore, the judgments of even "independent" psychiatrists are subject to bias and error. Accordingly, prospective patients at least should be given the opportumity to call psychiatrists who they believe are likely to agree with them that commitment is not necessary. If the prospective patient is indigent, the reasonable costs of retaming at least one psychiatrist, chosen by the prospective patient, should be borne by the state. If after examination the retained psychiatrist is not willing to testify on behalf of the prospective

187. United States v. Wade, 388 U.S. 218 (1967). See also, Gilbert v. California, 388 U.S. 263 (1967). The rule in Wade subsequently was limited to indicted or formally charged defendants. Kirby v. Illinois, 406 U.S. 682 (1972). On the other hand, since involuntary psychiatric interviews are a form of "custodial interrogation," Miranda v. Arizona, 384 U.S. 436 (1966), would support, by analogy, the right of a lawyer to be present at the psychiatric examination of his client.

188. E.g., Thornton v. Corcoran, 407 F.2d 695 (D.C. Cir. 1969); Lessard v. Schmidt, 349 F. Supp. 1078 (E.D. Wis. 1972), vacated on other grounds sub nom. Schmidt v. Lessard, 414 U.S. 473 (1974).

189. This point is discussed in ENnis \& Sieged, The Rights of Mental patients 285 (1973).

190. Id.

"Should the law then permit the illusion that the psychiatrist remains impartial and outside the adversary system? We think not." Dianond and Louisell, supra note 88 , at 1344.

In New York City and other jurisdictions the state's only representative at the commitment hearing is the examining psychiatrist; in effect, the supposedly neutral expert serves as complainant, prosecutor, and prosecution witness. 
patient he or she will have to go to trial without favorable psychiatric testimony. Even so, we believe this procedure should be given preference over the appointment of an ostensibly "independent" psychiatrist, as is presently done in several states. ${ }^{191}$ The rationale underlying this proposal is that the "independent" psychiatrist often testifies against the wishes of the prospective patient, with devastating impact on the minds of judges and jurors. ${ }^{192}$

\section{Nonjudicial Commitment Should Be Abolished Or Severely Circumscribed}

Our concern so far has been with the role of psychiatrists in judicial proceedings. In inany states, however, persons can be hospitalized involuntarily for inonths or even years without ever having appeared before a judge or jury. Typically, a certification by two psychiatrists-or even two physicians-that a person is mentally ill, or dangerous, or both, will suffice to authorize involuntary hospitalization. There is no evidence that psychiatric judgments made outside the judicial process are any more reliable or accurate than those made in a judicial context. Consequently, the former are just as vulnerable as the latter to the criticisms we have raised in this Article. Accordingly, involuntary hospitalization based on medical certification without benefit of a judicial determination of the necessity for lospitalization should no longer be permitted.

If medical certification is not abohshed, it should be permitted only in emergency situations, where the prospective patient is considered imminently dangerous to self or others. And medical certification slould authorize involuntary hospitalization only for the limited time necessary to institute judicial proceedings. Alternatively, if two psychiatrists, for example, can sign a person into a inental hospital, two other psychiatrists - perhaps retained by the patient or his friends - should be able to sign the patient out. The law should not presume that psychiatric judgments recommending hospitalization are inore valid than psychiatric judgments recommending release.

191. In In re Gannon, 123 N.J.S. 104, 301 A.2d 493 (Somerset Co. Ct. 1973), the court ruled that "in a commitment proceeding due process of law includes the right to an independent psychiatric examination" at state expense. That decision was based on the court's finding "that psychiatrists differ very definitely in their evaluations and diagnoses of mental illness. In a commitment proceeding . . . the right to counsel is of little value without a concurrent right to an independent psychiatric examination." See also N.Y. Judiciary LAw, § 35; Dixon v. Attorney General, 325 F. Supp. 966, 974 (M.D. Pa. 1971); Watson v. Cameron, 312 F.2d 878 (D.C. Cir. 1962) (Burger, J.); De Marcos v. Overholser, 137 F.2d 698 (D.C. Cir. 1943); People ex rel. Anonyinous No. 1 v. LaBurt, 17 N.Y.2d 738, 270 N.Y.S.2d 206, 217 N.E.2d 31 (1966).

192. Frequently, the "independent" psychiatrist is, or has been, a staff colleague of the psychiatrist or psychiatrists recommending hospitalization. 
In addition, since psychiatric judgments are strongly influenced by the context of the examination, all examinations should be conducted in the prospective patient's home or, if that is not possible, in an outpatient clinic. Prospective patients are likely to respond quite differently to the same questions if they are permitted to answer them in the familiarity of their own homes, rather than in a strange and possibly frightening hospital environment. In furtherance of this suggestion, whenever psychiatric examinations are conducted at a hospital or clinic, all psychiatrists who examine the prospective patient should be required to recommend for or against hospitalization. If there is disagreement, the prospective patient should remain at liberty pending judicial procedures. Specifically, a recommendation to commit by two psychiatrists should not be conclusive when one or more other psychiatrists on the staff disagree with that disposition. Only when the likelihood of imminent physical danger to the prospective patient or others is grave should an exception be made to this rule. Moreover, even then the prospective patient should be examined only in a quiet, homey section of the hospital in the presence of his friends, relatives, lawyer, or physician, if desired.

\section{D. "Mental Illness" and/or "Need for Care and Treatment" Should Not be Sufficient Grounds for Commitment}

There is no reason to believe that psychiatrists can determine who is "mentally ill" or predict who requires involuntary care and treatment any more rehably and accurately than they can make other diagnoses and predictions. Given the breadth and ambiguity of these terms, and the lack of any agreed definitions for them, such judgments are likely to be significantly less reliable and accurate than psychiatric judgments usually are.

At the least, therefore, no person should be involuntarily hospitalized on the basis of a judgment that the person is "mentally ill" or in need of care and treatment, when the only support for that judgment is the opinion of a psychiatrist. Furthermore, we have found no evidence that the judgment of who is "mentally ill," or who requires care and treatment, can be reliably and accurately made by anyone. In the present state of knowledge, commitment on these grounds is of necessity a completely arbitrary act. No person could be confined under the criminal law solely because of a judgment that the person is a "criminal type," because that standard is too imprecise to permit any test of the validity of the judgment. Similarly, no person should be confined under the civil law solely because of a judgment that the person is "inentally ill" or "in need of care and treatment," because these standards are too imprecise to permit any test of the validity of such judgments. 


\section{E. The Criteria for Commitment on the Basis of Dangerousness Should Be Severely Circumscribed}

Civil commitment of persons who have committed no crime but who nevertheless are thought to be "dangerous" is a form of preventive detention that is difficult to justify. We will not repeat here the constitutional and policy objections to such commitments. ${ }^{193}$ However, if civil commitment of allegedly dangerous persons is to be permitted at all, it should be severely circumscribed for there is no evidence that, in those cases in which dangerousness is brought into question, psychiatrists can predict dangerousness more accurately than laymen. To the contrary, the evidence suggests that psychiatrists are rather inaccurate predictors, more often wrong than right in close cases. Accordingly, no person should be committed when the only evidence that he or she is or will be dangerous is the opinion of a psychiatrist. Of course, the recognition that psychiatrists cannot tell us which persons are potentially dangerous of necessity leaves us without a firm basis on which to make those judgments. Unfortunately, as yet there is no easy or adequate way out of this dilemma, but until a more precise test or standard is devised, resort to time-honored assumptions about personal responsibility may be useful. One of the most fundamental assumptions we make about life is that the future will be pretty much like the past. People who have controlled their behavior in the past can probably be expected to control their behavior in the future. Although this assunption is sometimes wrong, it is correct often enough so that it affords a more rational basis for predicting dangerousness than the present reliance on psychiatric judgments.

Apphication of this common-sense approach to the civil commitment process would reduce substantially the risk of error, particularly the risk of overprediction. Under this approach, no person could be committed merely because of a prediction that the person will or may be dangerous in the future if the person has not actually done or threatened something dangerous in the recent past. We have seen that predictions of dangerous behavior are wrong inore often than they are right even in those cases in which the subject of the prediction has actually done or threatened something dangerous in the past. And without such evidence of past dangerous behavior, predictions of dangerous behavior are even more imaccurate. These findings raise considerable doubt about the utility and constitutionality of any statute

193. Those objections are discussed in Ennis, The Rights of Mental Patients, in The Rights of AMERicans 485-88 (Dorsen ed. 1970); Ennis, Mental Illness, 1969-1970 Annual Survey of AMerican Law 29, 45-48; Ennis, Civil Liberties and Mental Illness, 7 CRM. LAw BuLL. 101, passim (1971); Livermore, et al., supra note 78. 
which authorizes involuntary confinement on the ground of danger to self or others. But if such confinements are to be permitted, we should at least reduce the risk of error as much as possible by insisting on evidence of an overt act, attempt, or threat of a dangerous nature in the recent past. Absent such evidence, deprivations of liberty on the ground of dangerousness should be impermissible. Finally, the meaning of "dangerousness" should be spelled out more precisely because at present ambiguity of the term encourages over-prediction. The appropriate standard should require proof that in the absence of hospitalization there is a substantial likelihood that the prospective patient would inflict major physical injury upon self or others in the near future. ${ }^{194}$

\section{F. Commitment Should Require Proof of Mental Illness And Dangerousness Beyond a Reasonable Doubt}

Proof of guilt beyond a reasonable doubt is a constitutional requirement in criminal proceedings. ${ }^{105}$ Both the prospective patient and the accused criminal are subjected to a coercive process buttressed by the power of the state which may result in loss of liberty. The prospective patient, however, is afforded fewer procedural protections than we give those accused of crime. A substantial argument can be made that every procedural protection guaranteed to criminal defendants should be guaranteed to prospective patients. It is not necessary to go that far, however, in order to suggest that at least some of the procedural protections granted to criminal defendants would preserve important values and foster important objectives in the civil context as well, and should therefore be granted to prospective patients. One of those protections is the requirement of proof beyond a reasonable doubt. Those reasons were recently summarized in In Re Winship ${ }^{100}$ where the Supreme Court disregarded the civil-criminal distimction and held that proof beyond a reasonable doubt of the necessary facts in juvenile delinquency proceedings was required before the alleged juvenile delinquent could be "civilly" committed.

194. If the recommendations contained in this Section are adopted, the number of persons subject to involuntary hospitalization would be substantially dininished. Some persons would still be subject to involuntary hospitalization, but only upon evidence of overt acts or threats, the proof of which would not require subjective opinions or judgments. If a person truly requires involuntary hospitalization, there should be abundant and unambiguous evidence of that, and hence no need for opinions and predictions.

195. E.g., Speiser v. Randall, 357 U.S. 513, 520-26 (1958); Leland v. Oregon, 343 U.S. 790, 795 (1952); Holt v. United States, 218 U.S. 245, 253 (1910); Miles v. United States, 103 U.S. 304, 312 (1880).

196. 397 U.S. $358,363-64$ (1970). 
The requirement of proof beyond a reasonable doubt has this vital role in our criminal procedure for cogent reasons. The accused during a criminal prosecution has at stake interests of iminense importance, both because of the possibility that he may lose his liberty upon conviction and because of the certainty that he would be stigmatized by the conviction ... As we said in Speiser v. Randall, ... "There is always in litigation a margin of error, representing error in factfinding, which both parties must take into account. Where one party has at stake an interest of transcending valueas a criminal defendant his liberty-this margin of error is reduced as to him by the process of placing on the other party the burden of . . . persuading the factfinder at the conclusion of the trial of his guilt [beyond a reasonable doubt]." 197 (Emphasis added).

After Winship and In Re Gault ${ }^{188}$ it is irrelevant whether the purpose of the proceeding is therapeutic or punitive because the "good intentions" rationale was expressly rejected in those cases. They stand for the proposition that it is not the purpose but the consequence of the proceeding, "the awesome prospect of incarceration in a state institution," which inakes the criminal safeguards apphicable. ${ }^{199}$ Lower courts have followed the lead of the Supreme Court. In Denton v. Commonwealth, ${ }^{200}$ the Supreme Court of Kentucky ruled that the applicable burden of proof required in civil commitment proceedings was the same as that required in criminal actions. More recently, in Lessard $v$. Schmidt, ${ }^{201}$ and in In $\operatorname{Re}$ Ballay, ${ }^{202}$ federal courts have held that proof beyond a reasonable doubt of the prospective patient's mental illness and dangerousness is a constitutional requirement in a civil commitment proceeding. ${ }^{203}$

\section{CONCLUSION}

In 1964, Judge (now Chief Justice) Warren E. Burger wrote that psychology is, at best, an "infant among the family of science," that psychiatry and psychology cannot claim to be truly scientific, and that psychiatrists and psychologists "may be claiming too much in relation to what they really understand about the human personality and hu-

197. Id.

198. 387 U.S. 1 (1967).

199. In re Gault, 387 U.S. 1, 36-37 (1967). See also, Heryford v. Parker, 396 F.2d 393 (10th Cir. 1968).

200. 383 S.W.2d 681 (Ky. 1964).

201. 349 F. Supp. 1078 (E.D. Wis. 1972), vacated on other grounds sub nom. Schmidt v. Lessard, 414 U.S. 473 (1974).

202. 482 F.2d 648 (D.C. Cir. 1973).

203. See also Dixon v. Attorney General, 325 F. Supp. 966 (M.D. Pa. 1971) (requiring "clear and convincing" proof). 
man behavior."204 The professional literature confirms Justice Berger's intuitive judgment; psychiatrists have bitten off more than they can chew. The fault, however, is not theirs alone, for legislatures and courts, in an attempt to shift responsibility for making the determination of who shall remain free and who shall be confined, have turned to psychiatry, seeking easy answers where there are none.

Human behavior is difficult to understand, and, at present, impossible to predict. Subject to constitutional limitations, the decision to deprive another human of liberty is not a psychiatric judgment but a social judgment. We shall have to decide how much we value individual freedom; how much we care about privacy and self-determination; how much deviance we can tolerate - or how much suffering. There are no "experts" to make those decisions for us.

204. Burger, Psychiatrists, Lawyers, and the Courts, 28 FED. ProB, 3, 7 (1964). 